\title{
AvaliaÇÃo dos Componentes AnAtômicos do \\ Sistema Estomatognático de CriançAs COM BRUXISMO, POR MEIO de IMAGENS OBTIDAS POR Tomografia Computadorizada Cone Beam
}

Dissertação apresentada à Faculdade de Odontologia de Ribeirão Preto da Universidade de São Paulo, para obtenção do Título de Mestre em Ciências.

Programa: Odontopediatria.

Área de concentração: Odontopediatria.

Orientadora: Profa. Dra. KRANYA VICTORIA DÍAZ SERRANO 
Autorizo a reprodução e divulgação total ou parcial deste trabalho, por qualquer meio convencional ou eletrônico, para fins de estudo e pesquisa, desde que citada a fonte.

FICHA CATALOGRÁFICA

Sabbatini, Iliana Ferraz
Avaliação dos componentes anatômicos do sistema estomatognático de
crianças com bruxismo, por meio de imagens obtidas por tomografia
computadorizada cone beam. Ribeirão Preto, 2012.
76 p. : il. ; $30 \mathrm{~cm}$
Dissertação de Mestrado, apresentada à Faculdade de Odontologia de Ribeirão
Preto/USP. Área de concentração: Odontopediatria.
Orientadora: Díaz Serrano, Kranya Victoria
1.Bruxismo em crianças. 2.Tomografia Computadorizada Cone Beam. 3.Articulação
Temporomandibular




\section{FOLHA DE APROVAÇÃO}

SABBATINI, IF. AVALIAÇÃO DOS COMPONENTES ANATÔMICOS DO SISTEMA ESTOMATOGNÁTICO DE CRIANÇAS COM BRUXISMO POR MEIO DE IMAGENS OBTIDAS POR TOMOGRAFIA COMPUTADORIZADA CONE BEAM

Dissertação apresentada à Faculdade de Odontologia de Ribeirão Preto da Universidade de São Paulo, para obtenção do Título de Mestre em Ciências.

Programa: Odontopediatria.

Área de concentração: Odontopediatria.

Aprovado em:

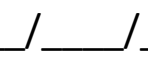

\section{Banca Examinadora}

Prof.Dr.

Instituição:

Julgamento: Assinatura:

Prof.Dr.

Instituição:

Julgamento:

Assinatura:

Prof.Dr.

Instituição:

Julgamento: Assinatura: 


\section{DADOS CURRICULARES}

\section{ILIANA FERRAZ SABBATINI}

Nascimento

28/03/1985 - São Roque - SP

Filiação

Marlene Ferraz Sabbatini

Paulo Roque Sabbatini

2005 - 2008 Curso de Graduação

Faculdade de Odontologia da Universidade de São Paulo - FORP/USP

2009 - 2011 Curso de Especialização

Associação Odontológica de Ribeirão Preto - AORP

2009 - 2012 Curso de Pós-Graduação em Odontopediatria, nível de Mestrado

Faculdade de Odontologia de Ribeirão Preto da Universidade de São Paulo - FORP/USP 
"No meio da dificuldade encontra-se a oportunidade." Albert Einstein 


\section{Dedico este trabalho,}

A Deus, primeiramente, que esteve comigo em todos os momentos da minha vida, pela minha família, por todos os meus amigos, por me ajudar a ser perseverante, me dar força e me guiar em todos os caminhos.

Aos meus pais, Marlene Ferraz Sabbatini e Paulo Roque Sabbatini, pela luta a fim de proporcionar a mim e à minha irmã as melhores condições para nossa formação e assim realizar nossos sonhos. Pelo amor incondicional, carinho e dedicação absoluta que sempre tiveram. Exemplos de simplicidade e sabedoria.

À minha irmã, Paola Ferraz Sabbatini, pelo amor e carinho, pelo incentivo em todos os meus passos, pelo companheirismo. Irmãos são amigos, ontem, hoje e sempre.

Ao meu extraordinário namorado, Antonio Rivas Galindo Neto, por todo afeto, carinho, compreensão, incentivo, paciência, companheirismo, ensinamentos e muito mais... Tenho profunda admiração por você e agradeço a Deus por tê-lo ao meu lado. Te gosto imensamente. 


\section{Agradecimentos especiais}

À minha orientadora, Profa. Dra. Kranya Victoria Díaz Serrano, que muito me ensinou durante todo o percurso deste trabalho. Muito obrigada pela sua paciência, dedicação, disponibilidade e apoio. A você todo o meu carinho e gratidão.

Às queridas amigas, Fernanda Regina Ribeiro Santos e Danielle Torres de Azevedo, pelo carinho, apoio, amizade, conversas, cumplicidade, desabafos, enfim, por serem pessoas maravilhosas e terem me acolhido tão intensamente. Uma amizade como a de vocês é uma verdadeira riqueza! Obrigada por tudo, $e$ saibam que vocês moram no meu coração!

Aos queridos amigos da graduação Daniela Yumie Takahashi, Glauce Crivelaro do Nascimento, João Victor Chiba Vieira, Juliana Pascoti Bruhn, Bruno José Rodrigues de Almeida, Gabriel Mascarin Minotti, Bruno Zampieri Amaral, Maria Beatriz Carrazzone Cal Alonso, Leonardo Raphael Zuardi e Bruno Rafael Brogiano Freschi. Obrigada pelos sorrisos, abraços, amizade, carinho, cumplicidade, momentos compartilhados, apoio nos momentos difíceis e por fazerem parte desta caminhada... Cada um de vocês tem um lugar especial em meu coração, e são pessoas das quais jamais esquecerei! 


\section{Agradecimentos}

À Faculdade de Odontologia de Ribeirão Preto da Universidade de São Paulo, na pessoa do seu diretor Prof. Dr. Osvaldo Luiz Bezzon e do Vice-Diretor Prof. Dr. Valdemar Mallet da Rocha Barros, que me acolhe e me engrandece desde a graduação.

À Coordenação do Programa de Pós-Graduação em Odontopediatria da Faculdade de Odontologia de Ribeirão Preto da Universidade de São Paulo, na pessoa da Coordenadora Profa. Dra. Léa Assed Bezerra da Silva e do ViceCoordenador Prof. Dr. Paulo Nelson Filho, pelo empenho na qualidade nesse conceituado Programa de Pós-Graduação.

À Coordenação de Aperfeiçoamento de Pessoal de Nível Superior (CAPES), pela bolsa de pesquisa concedida.

Aos Docentes do Departamento de Clínica Infantil, Odontologia Preventiva e Social da Faculdade de Odontologia de Ribeirão Preto da Universidade de São Paulo, Profa. Dra. Adelvina Campos de Freitas, Profa. Dra. Alexandra Mussolino de Queiroz, Profa. Dra. Léa Assed Bezerra da Silva, Profa. Dra. Kranya Victoria Díaz Serrano, Profa. Dra. Maria Cristina Borsatto, Prof. Dr. Paulo Nelson Filho, Profa. Dra. Raquel Bezerra da Silva, Profa. Dra. Andiara de Rossi e Profa. Dra. Sada Assed, pelo carinho, atenção e ensinamento.

Aos professores da banca, pela atenção dispensada na leitura desta dissertação. 
Aos funcionários do Departamento de Clínica Infantil, Odontologia Preventiva e Social da Faculdade de Odontologia de Ribeirão Preto da Universidade de São Paulo, Carmo Eurípedes Terra Barreto, Cleber Barbosa Rita, Dorival Gaspar, Matheus Morelli Zanela, Micheli Cristina Leite Rovanhoto, Vera Ribeiro do Nascimento, José Aparecido Neves do Nascimento, Filomena Leli Placciti.

Aos funionários do "Centro de Formação de Recursos Humanos Especializados no Atendimento Odontológico de Pacientes Especiais" da Faculdade de Odontologia de Ribeirão Preto da Universidade de São Paulo, Benedita Viana Rodrigues, Fátima Rizóli, Renata Aparecida Fernandes, pelo carinho e atenção de sempre.

Às secretárias da seção de Pós-Graduação da Faculdade de Odontologia de Ribeirão Preto da Universidade de São Paulo, Isabel Cristina Galino Sola e Regiane Cristina Moi Saciolotto, pela eficiente ajuda e atenção em todas as fases administrativas.

Às amigas do mestrado, Elaine Machado Pingueiro, Késsia Suênia Fidelis de Mesquita e Lígia Maria Napolitano Gonçalves, pela sincera amizade, risos, desabafos e momentos agradáveis que compartilhamos.

Aos colegas da Odontopediatria, Maya Fernanda Manfrin Arnez, Paula Dariana Fernandes Ferreira, Cristina Bueno Brandão, Marina Fernandes de Sena e Francisco Wanderley Garcia de Paula e Silva, pela convivência, carinho e apoio durante esta caminhada.

A todos que, de alguma forma, contribuíram para a realização deste trabalho, muito obrigada! 


\section{RESUMO}

Sabbatini, IF. Avaliação dos componentes anatômicos do sistema estomatognático de crianças com bruxismo, por meio de imagens obtidas por tomografia computadorizada cone beam. [dissertação]. Universidade de São Paulo, Faculdade de Odontologia de Ribeirão Preto, Ribeirão Preto, 2011. 76p.

Dentre as atividades parafuncionais do sistema estomatognático, pode-se salientar o bruxismo, o qual pode se manifestar tanto durante o sono (BS), quanto durante o dia (Bruxismo Diurno - BD) ocorrendo em distintos estados de consciência (sono e vigília). A Classificação Internacional dos Distúrbios do Sono define o bruxismo como "um distúrbio com movimentos de padrão desordenado do sistema mastigatório que envolve o ranger ou apertar dos dentes durante o sono". O diagnóstico de bruxismo é realizado clinicamente, com base no relato de uma história prévia recente de sons de ranger de dentes que ocorreram pelo menos de 3 a 5 noites por semana, durante 6 meses. A presença de facetas de desgaste dental, manifestações de dor matinal nos músculos mastigatórios, a hipertrofia do músculo masseter, a hipersensibilidade ou estalo da Articulação Temporomandibular (ATM), impressões dentais na bochecha ou língua e mobilidade dental, entre outros, são sinais característicos desta parafunção. Não obstante, frente à crescente valorização do aspecto funcional, a avaliação não deve se restringir apenas ao exame clínico. Nesse sentido, a imaginologia vem se tornando um recurso de valor inestimável para a determinação de um diagnóstico. Assim, o objetivo do presente trabalho é descrever as possíveis alterações dos componentes anatômicos da articulação temporomandibular (ATM), de crianças com bruxismo, por meio da análise de imagens obtidas pela técnica de Tomografia Computadorizada Cone Beam. Com base nos critérios de inclusão e exclusão, foram selecionados 20 indivíduos, entre 7 e 11 anos de idade, do sexo masculino e feminino, em atendimento na Clínica Infantil da FORP - USP. Na avaliação clínica para diagnóstico de bruxismo, foi evidenciado a presença de todas, ou algumas das seguintes alterações: presença de facetas de desgaste dental, fraturas de restaurações, fraturas dentais, impressões dentais em bochechas e língua, dor na ATM, ruído na ATM, dor nos músculos masseter e temporal. O exame tomográfico foi realizado em um aparelho de tomografia i-CAT e durante as reconstruções multiplanares, antes de gerar as imagens, o volume total do paciente foi transferido para o scanner com a utilização do plano de Frankfurt paralelo ao solo. Na análise de variáveis categóricas, utilizou-se teste Exato de 
Fisher e teste de Fisher com a extensão de Freeman-Halton. Foi considerado estatisticamente significante valor de $p \leq 0,05$. Em algum grau, todos os pacientes relataram dor à palpação dos músculos temporal e masseter, assim como à palpação da ATM. A presença de alterações na ATM somente apresentou significância estatística na presença de osteófitos na região articular do lado direito em associação com dor na articulação temporomandibular ipsilateral $(p=0,04)$. Erosões e esclerose não foram encontradas em nenhum paciente e aplainamento foi um achado na totalidade dos indivíduos, porém, não apresentando relação estatísticamente significante quando cruzado com achados clínicos.

A presença de dor no músculo temporal e a relação horizontal côndilo-fossa contralateral, apresentaram significância estatística $(p<0,05)$. No músculo masseter essa associação apresentou significância estatística com a relação horizontal côndilo-fossa ipsilateral $(p=0,01)$. Os achados sugerem que o bruxismo pode promover alterações significativas nas estruturas do sistema estomatognático desde a infância.

Palavras chave: Bruxismo em crianças; Tomografia Computadorizada Cone Beam; Articulação Temporomandibular. 


\section{ABSTRACT}

Sabbatini, IF. Evaluation of the anatomical structures of the stomatognathic system in children with bruxism by cone beam computed tomography. [dissertation]. University of São Paulo, Ribeirão Preto Dental School, Ribeirão Preto, 2011. 76p.

Among the parafunctional activities of masticatory system, bruxism can be higlighted. It occurs during sleep (Sleep Bruxism - SB) or wakefulness (Awake Bruxism - DB), which occur in two different states of consciousness (sleep and wakefulness). The International Classification of Sleep Disorders defines bruxism as "a movement disorder with a stereotyped pattern of the masticatory system that involves teeth grinding or clenching during sleep." Bruxism is clinically diagnosed based on reports of teeth grinding noises that occurred at least three to five nights per week for 6 months. Also, the presence of wear facets, matutinal pain in the masticatory muscles, masseter muscle hypertrophy, temporomandibular joint (TMJ) noise or hypersensitivity, dental impressions on the cheek or tongue and tooth mobility, among others, are hallmarks of this parafunction. However, the evaluation should not be restricted to clinical examination since functional aspects are gaining importance. As consequence, imaging has become an invaluable resource for diagnosis. The objective of this paper is to describe possible changes in temporomandibular joint (TMJ) anatomical components in children with bruxism by Cone Beam Computed Tomography image analysis. Based on the inclusion and exclusion criteria, Twenty 7-11years old male and female children treated at Ribeirão Preto Pediatric Dentistry Clinic, University of São Paulo, Brazil, were selected. The presence of all or some of the following changes was used in clinical evaluation for bruxism diagnosis in the present study: presence of wear facets, fractures in fillings, dental fractures, dental impressions in cheek and tongue, TMJ pain and clicking, masseter and temporalis muscles pain. The CT scan was performed on a i-CAT CT device and during multiplanar reconstructions, before obtaining image, the total volume of the patient was transferred to the scanner using the Frankfurt plane parallel to the ground. In Statistical analysis Fisher's exact test and Fisher's test with the FreemanHalton extension were used for categorical variables. Values of $p \leq 0.05$ were considered statistically significant. In the results, all patients reported pain on palpation of the temporalis and masseter muscles, as well as TMJ palpation. Erosions and sclerosis were not found. Flattening was present in all individuals, however, no statistical significance was found 
between this feature and clinical findings. The presence of osteophytes in the TMJ was associated with ipsilateral pain in temporomandibular joint palpation $(p=0.04)$. There was an association between pain in the contralateral temporal muscle and the condyle-fossa relationship in the horizontal direction $(p<0.05)$. There was also a correlation between pain in the ipsilateral masseter muscle and the condyle-fossa relationship in the horizontal direction ( $p=0.01$ ). In conclusion, our findings suggest that bruxism can promote significant changes in the structures of the stomatognathic system since childhood.

Keywords: Bruxism in children; Cone Beam Computed Tomography; Temporomandibular Joint. 


\section{SUMÁRIO}

1 INTRODUÇÃO__ 15

2 ProposiçÃo___ 21

3 Material e Métodos___ 23

3.1 Amostra__ 24

3.2 Avaliação clínica para diagnóstico de bruxismo__ 25

3.3 Avaliação tomográfica___ 30

3.4 Análise estatística__ 33

4 Resultados__ 34

5 DiscussÃo__ 42

6 ConClusão__ 47

REFERÊNCIAS_ $\quad 49$

ANEXOS_ 56 


\section{INTRODUÇÃ̃}




\section{INTRODUÇÃO}

O bruxismo é uma atividade parafuncional do sistema estomatognático que inclui apertamento e/ou rangimento dos dentes. É involuntário, não-funcional e rítmico (Ahmad,1986; Barbosa et al., 2008; Manfredini e Lobbezzo, 2009; Lavigne et al., 2008). Pode ocorrer em vigília, bruxismo diurno (BD) ou durante o sono (BS), sendo entidades diferentes, que ocorrem em distintos estados de consciência (sono e vigília), com envolvimento de diversos fatores etiológicos, devendo, portanto, ser diferenciadas (Bader e Lavigne, 2000; Lobbezoo e Naeije, 2001; Lobbezoo et al., 2008).

Pode ser classificado com base na relação maxilo-mandibular e dental, em bruxismo cêntrico e excêntrico. No bruxismo cêntrico, ocorre apertamento dental em oclusão cêntrica e/ou relação cêntrica, a contração muscular é isométrica, as facetas de desgaste dental não são características e os indivíduos com esse tipo de bruxismo, podem apresentar contatos prematuros cêntricos (Rodríguez et al., 2011).

Nos casos de bruxismo excêntrico, há apertamento e deslizamento dos dentes nas posições protusivas e latero-protusivas, as facetas de desgaste são excêntricas, tanto nos dentes anteriores como nos posteriores, e os contatos prematuros podem ser cêntricos ou excêntricos. A contração muscular é isométrica no apertamento e isotônica no deslizamento. Os movimentos mandibulares são bordejantes. Os indivíduos com bruxismo excêntrico apresentam dor, disfunção, hipertrofia muscular e sensibilidade á palpação (Rodríguez et al., 2011).

O bruxismo do sono é definido pela Classificação Internacional das Desordens do Sono como uma desordem de ranger ou cerrar os dentes somado a desgaste dental, sons ou desconforto muscular da mandíbula na ausência de uma desordem médica, estando associado com micro-despertares, que possuem um papel nos episódios motores anormais durante o sono destes pacientes (Kato et al., 2003a). Desta forma, é considerado como um distúrbio do sono (Bader et al., 2000; Kato et al., 2001b).

Durante essa atividade parafuncional, que ocorre quase que inteiramente em nível subconsciente, os mecanismos de proteção neuromusculares estão ausentes, o que pode acarretar danos ao sistema mastigatório (Vanderas e Manetas, 1995).

O bruxismo do sono não pode ser confundido com movimentos orofaciais normais que acontecem durante essa fase. Tais movimentos do padrão normal do sono devem ser diferenciados daquelas desordens que concomitantemente possam ocorrer nesse período. 
Movimentos Rítmicos Mastigatórios (RMMA), com ou sem ranger dos dentes, vem sendo relatados em pacientes normais e com bruxismo do sono. A maioria dos sinais clínicos (desgaste dental, hipertrofia do masseter) não é exclusiva do bruxismo, estes podem ser resultantes de outros hábitos e atividades durante a vigília (Kato et al., 2001a).

Com base nos fatores etiológicos, o bruxismo do sono (BS) é classificado como primário quando não há causa médica evidente, sistêmica ou psiquiátrica, e como secundário quando vem associado a um transtorno clínico, neurológico ou psiquiátrico, relacionado a fatores iatrogênicos (uso ou retirada de substâncias ou medicamentos) ou a outro transtorno do sono. A maioria dos casos de BS é de etiologia primária. (Pratap-Chand e Gourie-Devi, 1985; Lavigne e Montplaisir, 1994; Bader e Lavigne, 2000).

Para uma melhor compreensão do BS, é importante conhecer como o sono é estruturado. Nesse sentido é constituído de 3 a 6 ciclos em um intervalo de 60 a 90 minutos: (1) sono NREM (o chamado sono "tranquilo") que inclui sono leve (estágios 1 e 2) e o sono profundo (estágios 3 e 4 ou sono delta) e (2) o sono REM (os chamados "ativos" ou sono "paradoxal"). O primeiro momento do sono é caracterizado por uma dominância do sono NREM, enquanto que o sono REM domina o último período (Schenck e Mahowald, 2002; Lavigne et al., 2003).

O BS secundário pode estar representado por uma manifestação subclínica e precoce do distúrbio comportamental do sono REM (Tachibana et al., 1994; Schenck e Mahowald, 2002), diferenciando-se do BS primário que ocorre predominantemente no estágio 1 e ou 2 do sono NREM. Esta atividade neuromuscular oromandibular intensa e anormal é de caráter destrutivo e com sintomas clínicos intensos (Ware e Rugh, 1988; Bader e Lavigne, 2000).

Múltiplos fatores com diferentes pesos participam da fisiopatologia do BS primário. Acredita-se existir uma associação de alterações da neurotransmissão aminérgica no SNC, fatores psicológicos, transtornos oclusais e alterações do sono, na gênese do BS (Lobbezoo et al., 1997; Macaluso et al., 1998).

Basicamente, dois grupos de fatores etiológicos podem ser atribuídos a esta parafunção, fatores periféricos (morfológicos) e fatores centrais (patofisiológicos ou psicológicos), sendo que o bruxismo é principalmente regulado centralmente, e não por fatores periféricos (Lobbezoo e Naeije, 2001).

Não existe uma estrutura funcional e anatômica no SNC identificável como centro neural gerador específico de movimentos oromandibulares involuntários. Contudo, existem indícios da participação da neurotransmissão dopaminérgica, noradrenérgica e 
serotoninérgica na gênese e na modulação do bruxismo (Lobbezoo et al., 1997; Kato et al., 2003b).

No que diz respeito ao bruxismo em vigília (BD), as causas estão mais relacionadas a fatores psicológicos (Bader e Lavigne, 2000).

É unanimemente aceito na literatura científica a participação de múltiplos fatores na etiologia do bruxismo, até a influência de aspectos culturais tem sido relacionada. Tal é o caso da presença de parasitas intestinais a qual tem sido associada com esta parafunção, não havendo evidências científicas que sustentem essa hipótese, como comprovado por Díaz-Serrano et al. (2008).

É incontestável a afirmação de que existe associação entre o bruxismo e aspectos psicológicos, como ansiedade, estresse, depressão e outras características de personalidade e desordens emocionais (Ferreira - Bacci et al., In Press - BDJ/ 2012).

A incidência do bruxismo é muito variada, devido às diferentes metodologias utilizadas para o diagnóstico, variando entre 8,4\% e 32\% (Castelo et al., 2005; Fonseca et al., 2011). Em relação à sua prevalência, Serra-Negra et al. (2010) observaram a presença de bruxismo do sono em $35,3 \%$ das crianças avaliadas, das quais $52 \%$ eram meninas e $48 \%$ meninos.

Clinicamente, o bruxismo infantil pode ser relacionado com níveis de desgaste da superfície dentária e com desconfortos musculares e articulares. Além disso, devido às forças não axiais geradas nos dentes, pode atuar como um coadjuvante na progressão da doença periodontal destrutiva em crianças (Ahmad, 1986). Pode também acelerar a rizólise de dentes decíduos e provocar alterações na cronologia de erupção dos permanentes, bem como favorecer os apinhamentos dentais. Dessa forma, esse hábito bucal parafuncional deveria ser diagnosticado e controlado o mais precocemente possível (Okeson, 1989).

Pelo anteriormente exposto, se faz necessário abranger os diferentes aspectos vinculados a esta parafunção, para reconhecer os possíveis fatores de risco, assim como, para estabelecer um diagnóstico precoce dos primeiros sinais e sintomas e viabilizar a sua interceptação. Em virtude de ser considerado o mais deletério dos hábitos parafuncionais para o sistema estomatognático, a utilização de recursos clínicos e tecnológicos, capazes de detectarem possíveis alterações nas estruturas, é de grande importância.

$\mathrm{Na}$ atualidade, limitar o diagnóstico à avaliação clínica poderia ser questionável, uma vez que diversos instrumentos estão disponíveis, os quais oferecem informações ímpares para a determinação diagnóstica. Dentre estes instrumentos, podemos destacar as imagens, 
sendo uma das técnicas mais aprimoradas, na atualidade, a tomografia, a qual apresenta uma alta precisão para a avaliação dos componentes ósseos da ATM (Wiese et al., 2008).

Cabe salientar que a indicação de determinado exame radiográfico deve estar pautada na necessidade individual de cada paciente, na queixa principal e nos achados clínicos (Roberts et al., 2009).

As técnicas radiográficas convencionais oferecem imagens limitadas a duas dimensões, e estruturas complexas e tridimensionais são sobrepostas e visualizadas em apenas dois planos. Além da sobreposição dessas imagens, é também freqüente a ocorrência de distorções geométricas e volumétricas dos reparos anatômicos investigados (Vanderberghe et al., 2008). Assim, O aumento da utilização pelo clínico de exames e técnicas mais modernas e precisas é evidente. Nesse sentido, a tomografia computadorizada vem ganhando espaço na odontologia (Nagasawa et al., 2010; ).

Este recurso tem como vantagem a possibilidade de reconstrução direta dos pontos radiografados por reconstruções axiais, coronais e sagitais. As imagens na Tomografia Computadorizada Cone Beam (TCCB) são capturadas por uma única varredura do scanner e reconstruídas digitalmente em pontos tridimensionais ou voxels (pixel 3D), permitindo um exame rápido, preciso e com uma exposição relativamente pequena do paciente à radiação (Stechow et al., 2003; Vassileva e Stoyanov, 2010).

A dose de radiação recebida pelos pacientes durante a realização de uma TCCB para fins odontológicos é considerada pequena quando comparada com a dose recebida pelos pacientes submetidos à TC para procedimentos médicos (Chau e Fung, 2009; Suomalainen et al., 2009; Jervoe-Storm et al., 2010). Já a dose de radiação emitida pela técnica TCCB em relação às técnicas convencionais radiográficas, utilizadas na odontologia é significativamente maior (Roberts et al., 2009). Porém em métodos convencionais radiográficos (radiografias panorâmicas e cefalométricas) não conseguimos observar com clareza regiões como a Articulação Temporomandibular (ATM), necessitando de um exame imaginológico mais preciso e detalhado para esse fim.

A técnica de TCCB vem sendo aplicada em várias áreas da odontologia como na implantodontia, na cirurgia, para diagnósticos orais, entre outros (Lascala et al., 2004). Quando da sua utilização na área de odontopediatria especificamente, destaca-se a possibilidade de avaliação das estruturas de suporte dos dentes e dos elementos ósseos da articulação temporomandibular (ATM); permitindo assim realizar um melhor diagnóstico, bem como evidenciar as alterações estruturais decorrentes do bruxismo em períodos precoces da vida. 
A TCCB fornece várias vantagens sobre as radiografias panorâmicas e a tomografia convencional. Ela permite a observação dos componentes ósseos nos três planos, fornecendo excelente visualização de possíveis mudanças (Librizzi et al., 2011; Wiese et al., 2011). Alterações visíveis radiograficamente são precedidas por alterações ósseas e na cartilagem articular que não se manifestam o suficiente para ser detectadas. Assim, os sinais clínicos e sintomas podem parecer pobres em relação aos achados radiográficos (Wiese et al., 2008).

Pullinger e White (1995) avaliaram a eficácia de tomografias da ATM em termos de resultados esperados e achados atuais e descobriram que as tomografias adicionaram novas informações com relação a descobertas ósseas inesperadas, bem como mudanças na posição do côndilo.

Diretrizes para a análise da imagem da ATM têm sido sugeridas (Brooks et al., 1997; White et al., 2001). Porém, ainda não existe um protocolo bem definido. Na tentativa de determinar pautas protocolares para essa avaliação e análise, alguns estudos vêem sendo realizados (Omnell e Petersson, 1976; Hintze et al., 2007; Wiese et al., 2007; Wiese et al., 2008) avaliaram a presença de alterações morfológicas no côndilo (aplainamento, defeitos e osteófitos) e do tubérculo articular (aplainamento e defeitos). Wiese et al. (2011), também avaliaram achados de alterações degenerativas (aplainamento, erosão, osteóficos e esclerose), além da presença de osteoartrite e osteoartrose.

Com base no marco teórico, se torna evidente a necessidade do conhecimento morfofisiológico das estruturas do sistema estomatognático e da correta avaliação das possíveis alterações resultantes do impacto que, parafunções como o bruxismo, possam vir a se manifestar. Uma desarmonia morfo-funcional em uma criança ou adolescente, além de prejudicial por si só, pode resultar, se persistente, em uma condição patológica severa e irreversível.

Paralelamente, com os avanços na tecnologia digital, as novas técnicas de imagem, como a tomografia computadorizada cone beam, mostra detalhes anatômicos importantes dos componentes do sistema estomatognático, facilitando o diagnóstico precoce e o tratamento de inúmeras patologias. 
ProposiçÃ̃o 


\section{ProposiçÃo}

Considerando-se que qualquer alteração nos elementos do sistema estomatognático pode repercutir na harmonia de seu desenvolvimento e conseqüentemente no seu equilíbrio morfofuncional, o presente estudo teve como objetivo descrever as alterações dos componentes da Articulação Temporomandibular (ATM), de crianças com bruxismo, entre 7 e 11 anos de idade, por meio de imagens obtidas por Tomografia Computadorizada Cone Beam. 
Material e Métodos 


\section{Material e Métodos}

O projeto da presente pesquisa foi previamente submetido à apreciação do Comitê de Ética em Pesquisa em Seres Humanos da Faculdade de Odontologia de Ribeirão Preto USP (Processo $n^{\circ}$ 2010.1.965.58.0), de acordo com a resolução 196/96 do Conselho Nacional de Saúde, tendo sido aprovado.

\subsection{Amostra}

Inicialmente foi realizada uma triagem das crianças em atendimento na Clínica de Odontopediatria da Faculdade de Odontologia de Ribeirão Preto da Universidade de São Paulo, Brasil. Foi considerado o relato positivo de bruxismo na criança, por parte dos pais e/ou responsáveis. Selecionados os pacientes, eles foram chamados para avaliação clínica.

Os critérios de inclusão para a seleção da amostra consistiram, além do relato dos pais e/ou responsáveis sobre manifestação de bruxismo nas crianças, de 3 a 5 vezes por semana, nos últimos três meses; as mesmas deviam se encontrar na faixa etária entre 7 e 11 anos e em fase de dentição mista. Foram excluídas as crianças que apresentavam doenças sistêmicas, que estavam em uso de medicamentos que interferem na atividade muscular e no sono (anti-histamínicos, sedativos, homeopatia ou outras drogas depressoras do Sistema Nervoso Central), com presença de dor de origem dental o que se encontravam sob tratamento ortodôntico, terapia fonoaudiológica ou otorrinolaringológica.

Com base nos critérios supracitados, 27 pacientes participaram da segunda fase, que consistiu de avaliação para o diagnóstico clínico de bruxismo. Durante o desenvolvimento do trabalho, cinco (5) pacientes não apresentaram sinais e sintomas que caracterizam o diagnóstico clínico de bruxismo, um (1) estava sob tratamento ortodôntico e um (1) não compareceu à terceira fase que se compreendeu de avaliação tomográfica. A amostra final foi composta por 20 crianças, de ambos os sexos, com idade entre 7 e 11 anos. 
Os pais e/ou responsáveis pelas crianças foram informados sobre os propósitos e etapas da pesquisa, possíveis desconfortos e riscos, bem como sobre os benefícios. Posteriormente assinaram o termo de consentimento livre e esclarecido, de forma espontânea.

\subsection{Avaliação clínica para diagnóstico de bruxismo}

Os dados para diagnóstico de bruxismo foram anotados em fichas, considerando-se três aspectos principais:

1. Dados Pessoais: consistiram de questões relativas ao nome da criança, nome do responsável, idade da criança, data de nascimento, escolaridade, endereço e telefone para contato.

2. Entrevista: os responsáveis foram entrevistados por um único examinador calibrado. Foi aplicado um questionário de anamnese estruturado e padronizado. $O$ questionário constituiu-se de questões qualitativas (sim e não) e quantitativas (sempre, às vezes, quase nunca) inerentes ao comportamento e hábitos cotidianos da criança, à presença de parafunções, dores de cabeça, ocorrência de sons audíveis durante o sono (rangimento dental), características do sono no que diz respeito à manifestação de outras parasomnias, dores faciais ao acordar, dores durante a mastigação.

3. Exame clínico específico: inicialmente foram avaliados o peso e a altura, partindo então para as avaliações específicas:

3.1 Facetas de desgaste dental: neste exame a criança foi colocada na posição semi - inclinada, direcionada para uma fonte abundante de luz. Com o auxílio de uma espátula de madeira e jato de ar, foi avaliada a presença ou não de desgaste. Os dados obtidos foram classificados de acordo com Nilner (1983), da seguinte forma:

- Grau 0 - Não apresenta

- Grau 1 - Somente no esmalte

- Grau 2 - Dentina exposta

- Grau 3 - Desgaste severo/exposição pulpar 


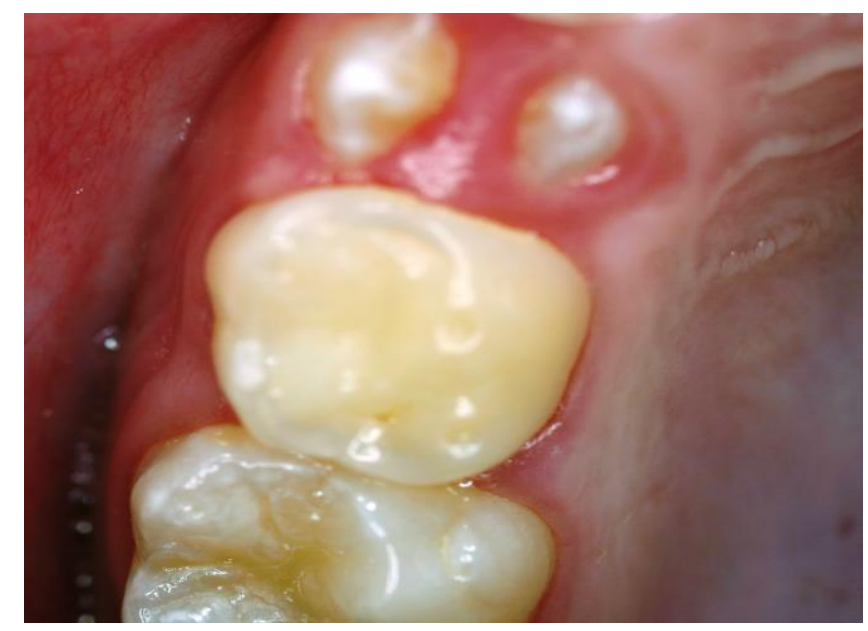

Figura 1. Faceta de Desgaste Grau 1

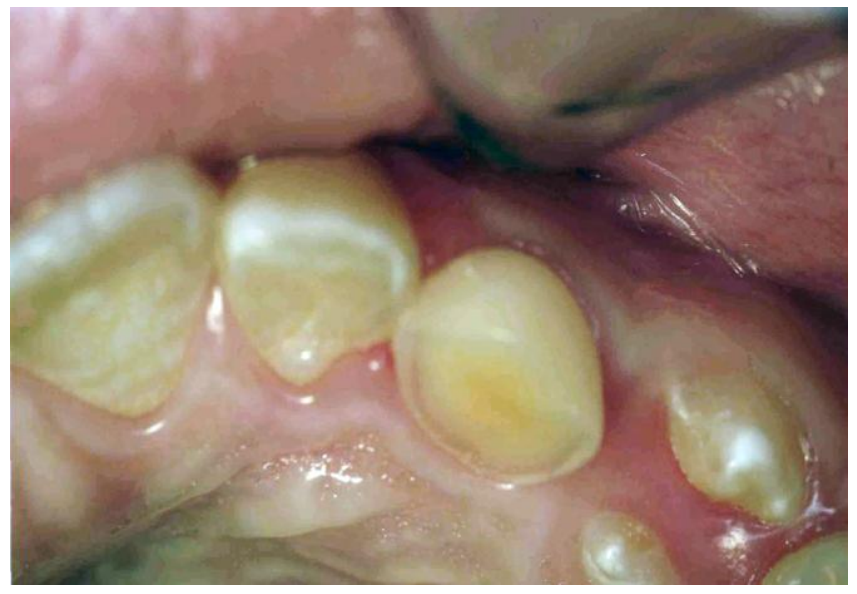

Figura 2. Faceta de Desgaste Grau 2

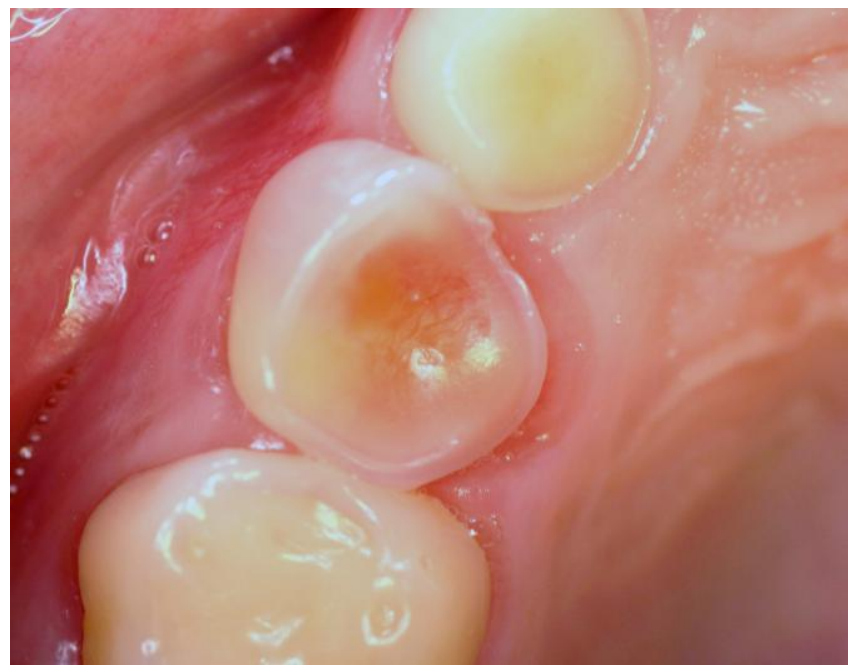

Figura 3. Feceta de Desgaste Grau 3 
3.2 Fratura dental e fratura de restaurações: neste exame a criança manteve a posição descrita anteriormente e a avaliação seguiu o mesmo padrão. Os dados obtidos foram classificados de forma qualitativa (sim e não), indicando o(s) elemento(s) afetado(s).

3.3 Impressões dentais em bochechas e língua: Com o auxílio de uma espátula de madeira foi observada a presença ou ausência de impressões dentais, para ambos os lados de cada estrutura.

3.4 Avaliação da ATM: neste exame a criança foi colocada sentada com o tronco em posição ereta e a cabeça apoiada. O deslocamento posterior e lateral foi avaliado por palpação digital sobre a área da ATM durante os movimentos de abertura e fechamento bucal. A sensibilidade ou dor manifestada pelo paciente durante o procedimento foi registrada com o auxílio de uma escala analógica visual e diferenciada entre os lados. Também foi avaliada a presença ou não de ruídos articulares com o auxílio de um estetoscópio.

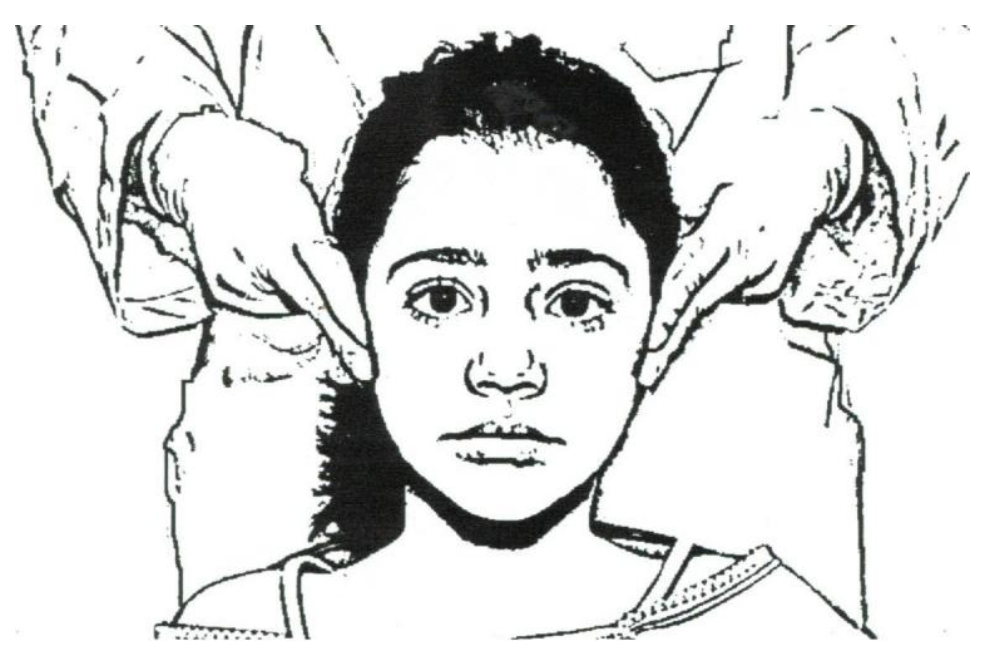

Figura 4. Palpação bilateral da ATM 
3.5 Palpação Muscular: foram palpados os grupos temporal e masseter, o esternocleidomastóideo, os músculos cervicais e trapézios. Foram registradas as diferenças entre os lados, inerentes às manifestações de sensibilidade ou dor, referidas pelo paciente, com o auxílio de uma escala analógica visual.

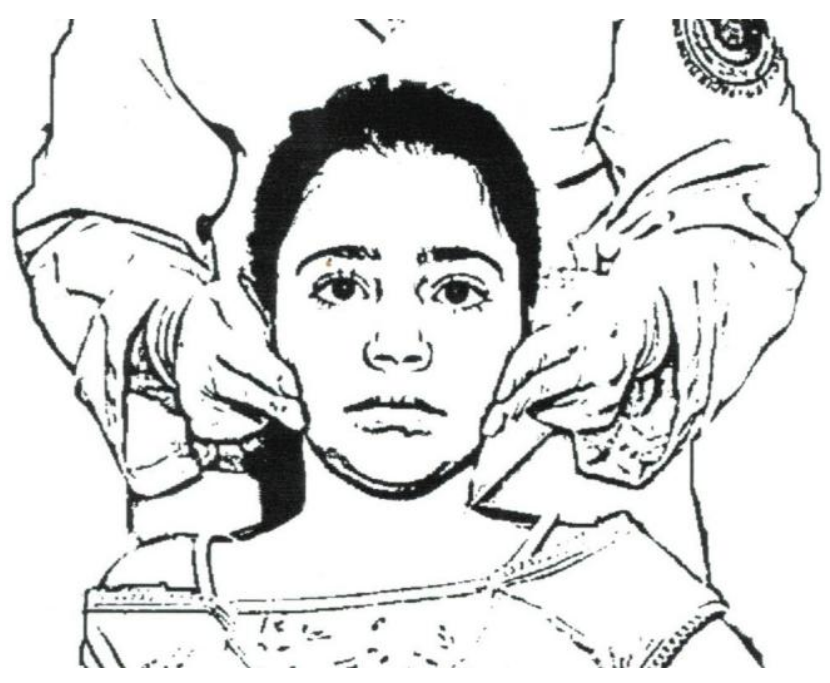

Figura 5. Palpação dos músculos masseter direito e esquerdo

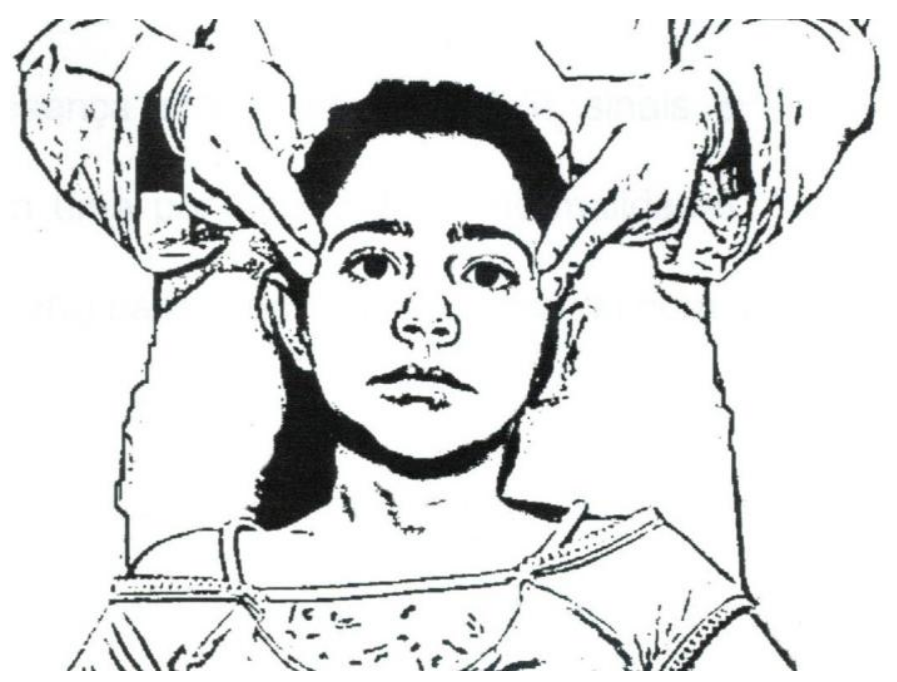

Figura 6. Palpação dos músculos temporal direito e esquerdo 


\subsection{Avaliação da Oclusão:}

a) Relação Interdental: Foi utilizada a classificação de Angle

b) Movimentos Mandibulares:

b.1) Máxima Abertura Bucal: Neste exame a criança foi colocada sentada com o tronco em posição ereta e a cabeça apoiada, procurando-se manter o plano oclusal paralelo ao solo, direcionada para uma fonte abundante de luz natural. Foram incorporados elementos lúdicos solicitando à criança unir os dedos indicador-médio-anelar e, posteriormente, abrir ao máximo a boca, levando os dedos ao interior desta. Foi medido o valor em $\mathrm{mm}$ dos três dedos juntos. $\mathrm{O}$ dado obtido foi classificado considerando-se que o valor normal de abertura bucal em crianças oscila, segundo a literatura específica, entre 35 e $40 \mathrm{~mm}$ :

- 1 a 2 dedos - limitação severa

- 2 a 3 dedos - limitação moderada

- Mais de 3 dedos - sem limitação

b.2) Trajetória de abertura e fechamento bucal: neste exame, a criança manteve a posição descrita anteriormente. Tal procedimento foi realizado observando-se o paciente de frente, colocando na ponta do nariz um fio dental cujo comprimento chegou além do mento, o qual serviu de referência na verificação do trajeto no movimento e fechamento bucal. Uma diferença maior que $2 \mathrm{~mm}$ entre o fio e a mandíbula durante o procedimento foi considerada desvio.

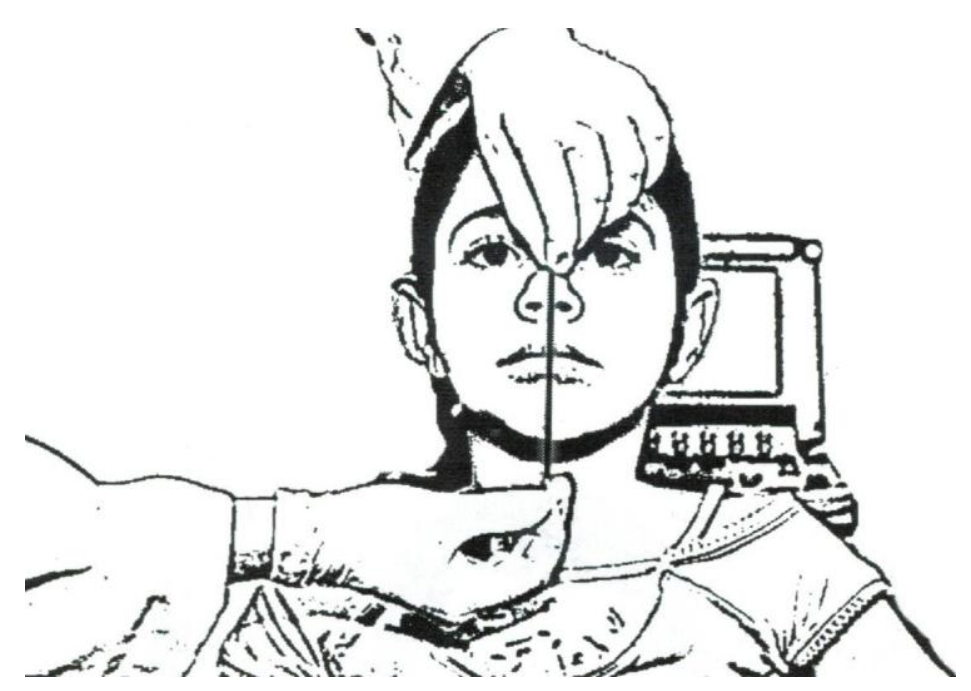

Figura 7. Trajetória de abertura e fechamento bucal 


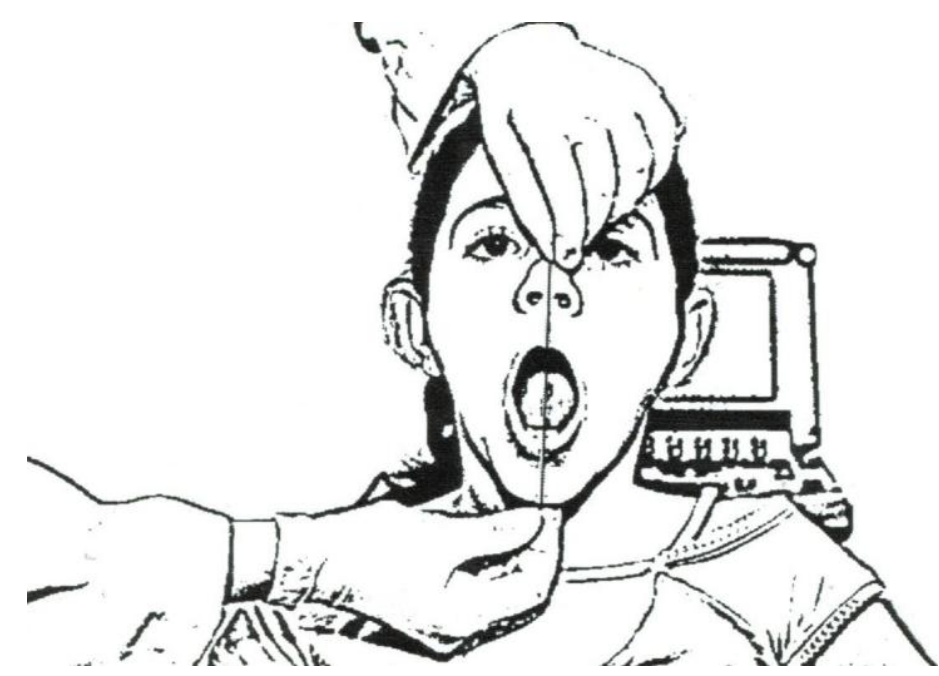

Figura 8. Trajetória de abertura e fechamento bucal

Para o diagnóstico positivo de bruxismo foi considerado o relato dos pais ou responsáveis referente à manifestação de apertamento e/ou rangimento dental (durante o sono ou vigília), associado à avaliação clínica. Nesta última foi evidenciado a presença de todas, ou algumas, das seguintes alterações: presença de facetas de desgaste dental, fraturas de restaurações, fraturas dentais, impressões dentais em bochechas e língua, dor na ATM, ruído na ATM, dor nos músculos masseter e temporal.

\subsection{Avaliação tomográfica}

Após avaliação clínica para diagnóstico de bruxismo, os pacientes que se disponibilizaram a realizar os exames tomográficos, foram encaminhados para a clínica DVI (Diagnóstico Volumétrico por Imagem - situada à Rua Sete de Setembro, 949 na cidade de Ribeirão Preto - SP) sobre a supervisão do Dr. Fernando G. Junqueira Leite (CROSP 75381) e com o acompanhamento dos responsáveis pelas crianças e responsáveis pelo projeto.

O exame foi realizado em um aparelho de tomografia i-CAT. O dispositivo foi operado a 1-3 mA e 129 k VCP usando um gerador de alta freqüência com anado fixo, tamanho do ponto focal luminar $0,5 \mathrm{~mm}$, o que proporcionou a obtenção de imagens em uma 
única rotação de $360^{\circ}$, varredura de 20 segundos abrangendo 306 projeções de base, com um campo de $17 \mathrm{~cm}$ de diâmetro por $13,5 \mathrm{~cm}$ de altura usando um software de obtenção iCAT (versão 1.7.7). Reconstruindo automaticamente os dados em "tempo real" resultando em 330 lâminas individuais de $0,2 \mathrm{~mm}$ em cada plano ortogonal.

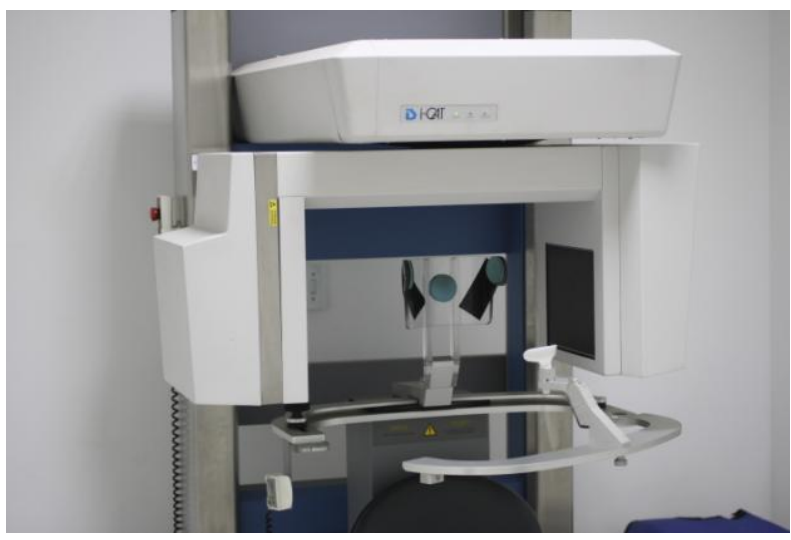

Figura 9. Tomógrafo i-CAT

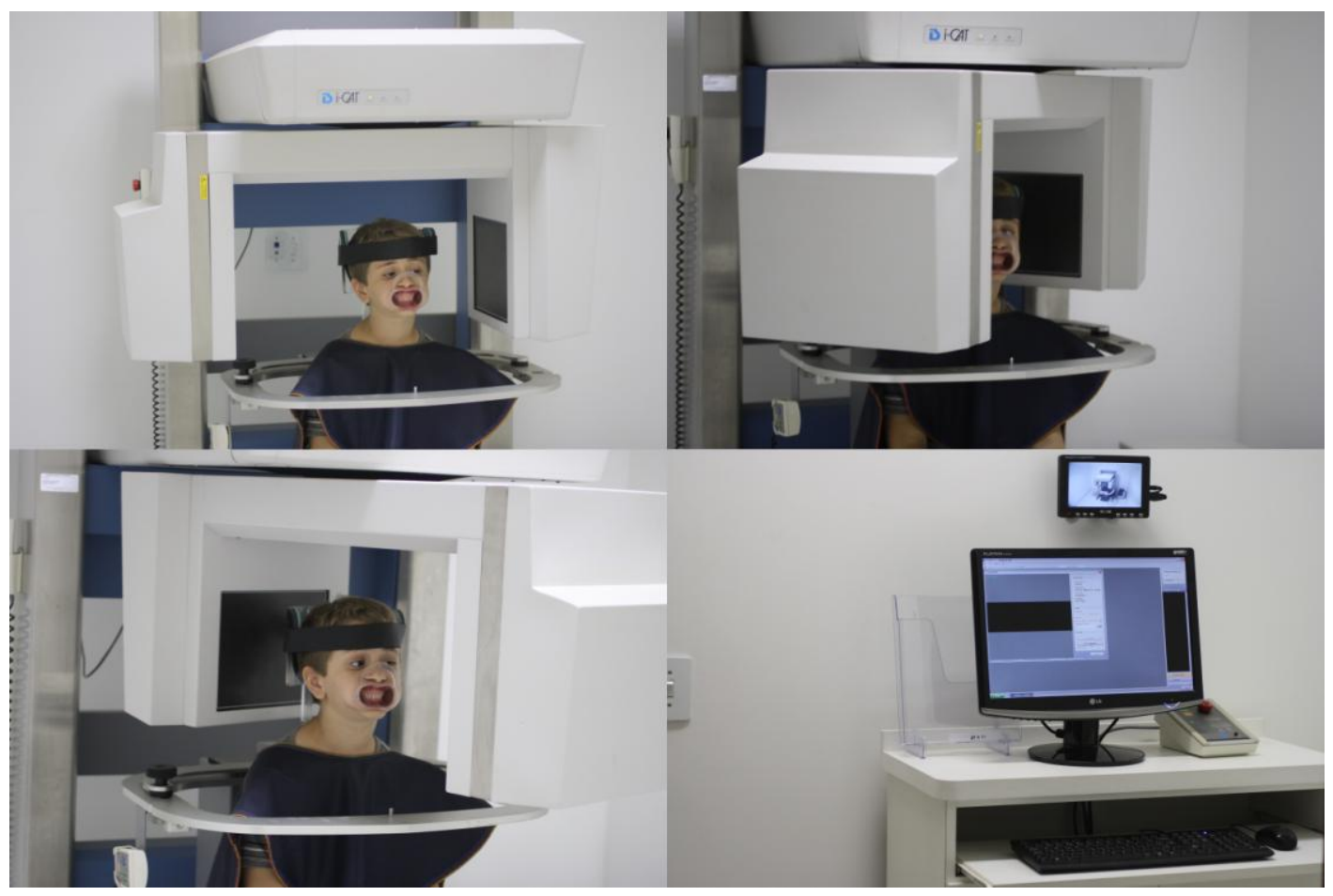

Fugura 10. Realização do exame tomográfico 
Durante as reconstruções multiplanares, antes de gerar as imagens, o volume total do paciente foi transferido para o scanner com a utilização do plano de Frankfurt paralelo ao solo.

Para avaliação das estruturas anatômicas da Articulação Temporomandibular (ATM), pela TCCB, parâmetros utilizados para este fim em diversos relatos científicos, serviram como base (Pullinger e White, 1995; Brooks et al., 1997; White et al., 2001; Hintze et al., 2007; Wiese et al., 2008; Wiese et al., 2011).

Os dados obtidos foram classificados de forma qualitativa (sim e não) e categorizados conforme descrito abaixo:

-Presença de alteração em qualquer uma das estruturas da ATM.

-Presença de osteoartrite (processo inflamatório da articulação caracterizado pelo aumento do espaço intra-articular).

-Presença de osteoartrose (alteração degenerativa da articulação caracterizada pela diminuição do espaço intra-articular).

-Assimetrias dos lados direito e esquerdo.

-Aplainamento (perda da convexidade/concavidade dos contornos conjuntos).

-Presença de osteófito (locais de excrescência óssea decorrentes da superfície mineralizada).

-Presença de erosão (área de rarefação na camada compacta de osso).

-Presença de esclerose (aumento de radiopacidade do osso esponjoso ou espessamento do osso compacto).

Os achados morfológicos não foram especificados para os componentes de forma separada (côndilo, fossa e eminência articular), mas o conjunto foi avaliado como uma unidade.

A relação côndilo-fossa foi avaliada somente na posição fechada. Foi classificada no sentido horizontal como sendo anteriorizada, centralizada e posteriorizada e no sentido vertical como sendo inferior, central e superior. 


\subsection{Análise estatística}

Foram cruzados dados da avaliação clínica (facetas de desgaste, fraturas dentais, fraturas de restaurações, impressão dental em língua e bochechas, overjet, desvio de linha média, mordida cruzada posterior, trajetória de abertura e fechamento, dor e ruídos na ATM e dor nos músculos temporal e masseter) com dados da avaliação tomográfica (presença de assimetrias, osteófitos, esclerose, erosão e aplainamentos, relação horizontal côndilo-fossa, relação vertical côndilo-fossa), porém nos resultados só foram consideradas associações que apresentaram significância estatística.

$\mathrm{Na}$ análise de variáveis categóricas, utilizou-se teste Exato de Fisher e teste de Fisher com a extensão de Freeman-Halton. Foi considerado estatisticamente significante valor de $p \leq 0,05$. 
RESUltados 


\section{Resultados}

Participaram do estudo 20 pacientes, $80 \%$ do sexo masculino $(n=16)$ e $20 \%$ do sexo feminino $(n=4)$ com idade média de $8.85 \pm 1.53$ anos e relato associado ao diagnóstico clínico de bruxismo.

Foram encontradas facetas de desgaste em $95 \%$ dos pacientes $(n=19)$. Impressão dental em bochecha em $85 \%$ dos pacientes $(n=17)$, impressão dental em língua em $10 \%$ dos pacientes $(n=2)$. Todos os pacientes referiram dor à palpação dos músculos mastigatórios e/ou da ATM. Outras características dos pacientes em estudo encontram-se detalhadas nas tabelas 1,2 e 3 .

Dor no músculo temporal bilateral à palpação, com diferentes graus de severidade, esteve presente na totalidade dos casos, havendo associação estatisticamente significante entre esta manifestação e a relação côndilo-fossa no sentido horizontal (tabelas 4 e 5). Houve significância na associação entre dor leve no temporal esquerdo e o côndilo localizado numa posição anteriorizada (figura 11A) do lado direito $(p=0,03)$. De igual modo essa dor contralateral foi manifesta de forma moderada no temporal direito, quando o côndilo estava localizado numa posição centralizada (figura 11-B) do lado esquerdo $(p=0,04)$.

Ainda no sentido horizontal, da relação côndilo/fossa, a dor no músculo masseter do lado direito apresentou associação estatisticamente significante $(p=0,01)$, caracterizando uma dor ipsilateral, como descrito na tabela 6. Essa significância foi observada quando da presença de dor leve e a localização anteriorizada do côndilo (figura 11-A) e a presença de dor severa quando o côndilo estava localizado numa posição posteriorizada (figura 11-C).

A presença de osteófitos (figura12-A) na região articular do lado direito apresentou associação com dor na articulação temporomandibular ipsilateral $(p=0,04)$, Tabela 7. Significância para presença de osteófitos e dor intensa.

Erosão e esclerose não foram encontradas em nenhuma das crianças. Todos os pacientes apresentaram aplainamento (figura 12-B), no entanto, sem relação estatisticamente significante com outras variáveis do estudo. Assimetrias da posição condilar direita em relação ao lado esquerdo foram encontradas em $60 \%$ do pacientes $(n=12)$, mas também não apresentou significância estatística quando cruzada com outras variáveis. 


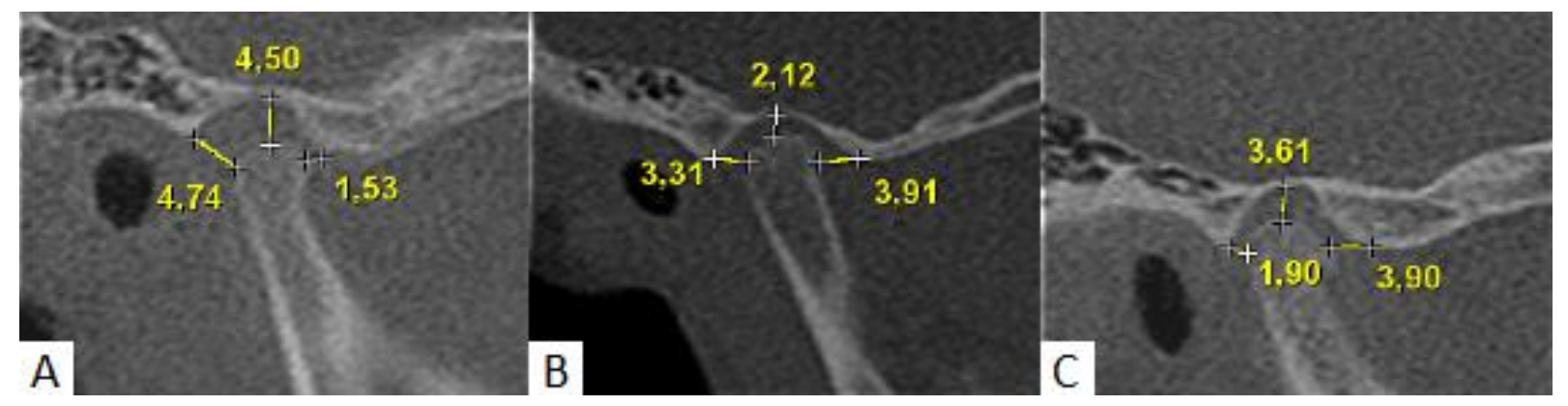

Figura 11. Relação Côndilo/Fossa Horizontal
A - Anteriorizada
B - Centralizada
C - Posteriorizada

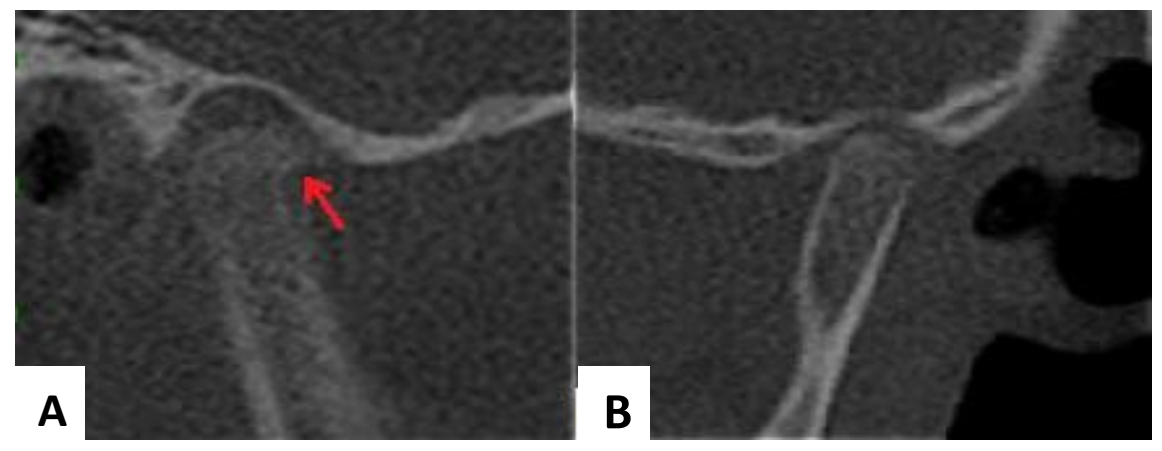

Figura 12. Alterações Morfológicas

A - Osteófito

B - Aplainamento 
Tabela 1. Frequência dos achados clínicos.

\section{Achados Clínicos}

Facetas de Desgaste Dental

Sim

Não

Impressão Dental em Bochecha

Sim

Não

Impressão Dental em Língua

Sim

Não

Fratura Dental

Sim

Não

Fratura de Restaurações

Sim

Não
Frequência Percentagem

(n)

$1 \quad 5 \%$

$17 \quad 85 \%$

$315 \%$

$2 \quad 10 \%$

$18 \quad 90 \%$

$4 \quad 20 \%$

$16 \quad 80 \%$

$2 \quad 10 \%$

$18 \quad 90 \%$


Tabela 2. Frequência da presença de dor à palpação.

\section{Presença de Dor}

Frequência

(n)

Dor no Temporal - Lado Direito

Leve

Moderada

Severa

Dor no Temporal - Lado Esquerdo

Leve

Moderada

Severa

Dor no Masseter - Lado Direito

Leve

Moderada

Severa

Dor no Masseter - Lado Esquerdo

Leve

Moderada

Severa

15

4

1

$20 \%$

$5 \%$

16

$80 \%$

3

$15 \%$

1

$5 \%$

13

3

4

$65 \%$

$15 \%$

$20 \%$

10

$50 \%$

7

3

$35 \%$

$15 \%$

Dor na ATM - Lado Direito

Leve

Moderada

Severa

12

6

2

$60 \%$

$30 \%$

$10 \%$

Dor na ATM - Lado Esquerdo

Leve

Moderada

13

$65 \%$

5

$25 \%$

Severa

$10 \%$

Dor durante a Mastigação

Sim

6

$30 \%$

Não

14 
Tabela 3. Frequência dos achados tomográficos.

\section{Achados Tomográficos Frequência (n) Percentagem}

Presença de Assimetrias

Sim

Não
12

8

11

4

5

Posteriorizada

Relação Côndilo-Fossa no

Sentido Horizontal - Lado Direito

Anteriorizada

Centralizada

Relação Côndilo-Fossa no

Sentido Horizontal - Lado Esquerdo

Anteriorizada

Centralizada

Posteriorizada

$60 \%$

$40 \%$

Relação Côndilo-Fossa no

Sentido Vertical - Lado Direito

Inferior

Central

3

16

$15 \%$

Superior

1

$80 \%$

$5 \%$

Relação Côndilo-Fossa no

Sentido Vertical - Lado Esquerdo

$$
\begin{aligned}
& \text { Inferior } \\
& \text { Central } \\
& \text { Superior }
\end{aligned}
$$

Presença de Osteófitos - Lado Direito

Sim

Não

Presença de Osteófitos - Lado Esquerdo 
Tabela 4. Relação Côndilo/Fossa no sentido horizontal associada à dor no músculo temporal contralateral.

Relação Côndilo-Fossa no Sentido Horizontal - Lado Direito

Anteriorizada

Centralizada
Dor no músculo Temporal

Lado Esquerdo

Leve Moderada Severa

$\begin{array}{rrr}11 & 0 & 0 \\ 68,8 \% & 0 \% & 0 \% \\ 3 & 1 & 0 \\ 18,8 \% & 33,3 \% & 0 \% \\ 2 & 2 & 1 \\ 12,5 \% & 66,7 \% & 100,0 \%\end{array}$

$\mathrm{P}=0,03$. Teste Fisher/ Freeman-Halton

Tabela 5. Relação Côndilo/Fossa no sentido horizontal associada à dor no músculo temporal contralateral.

\begin{tabular}{lrrr}
\hline Relação Côndilo-Fossa no & \multicolumn{3}{c}{ Dor no músculo Temporal } \\
Sentido Horizontal - Lado Esquerdo & \multicolumn{2}{c}{ Lado Direito } \\
\cline { 2 - 4 } & Leve & Moderada & Severa \\
Anteriorizada & 7 & 0 & 0 \\
Centralizada & $46,7 \%$ & $0 \%$ & $0 \%$ \\
& 6 & 4 & 0 \\
Posteriorizada & $40,0 \%$ & $100,0 \%$ & $0 \%$ \\
& 2 & 0 & 1 \\
& $13,3 \%$ & $0 \%$ & $100,0 \%$ \\
\hline
\end{tabular}

$\mathrm{P}=0,04$. Teste Fisher/ Freeman-Halton 
Tabela 6. Relação Côndilo/Fossa no sentido horizontal associada à dor no músculo masseter ipsilateral.

Relação Côndilo-Fossa no

Sentido Horizontal - Lado Direito

Leve

Anterioriorizada

Centralizada

\begin{tabular}{rrrr} 
& $15,4 \%$ & $33,3 \%$ & $25,0 \%$ \\
Posteriorizada & 1 & 1 & 3 \\
& $7,7 \%$ & $33,3 \%$ & $75,0 \%$ \\
\hline
\end{tabular}

$\mathrm{P}=0,01$. Teste Fisher/ Freeman-Halton

Tabela 7. Relação entre presença de osteófitos e dor na ATM.

Dor no músculo Masseter

Lado Direito

Moderada Severa

10

1

0

$76,9 \%$

$33,3 \%$

$0 \%$

2

1

1

3
Osteófitos - Lado Direito

\section{Dor na ATM - Lado Direito}

Leve Moderada Severa

Sim

$\begin{array}{r}4 \\ 33,3 \% \\ \hline\end{array}$

5

2

Não

8

$83,3 \%$

$100,0 \%$

1

0

$66,7 \%$

$16,7 \%$

$0 \%$

$\mathrm{P}=0,04$. Teste Exato de Fisher 
Discussão 


\section{Discussão}

No organismo humano existem mecanismos de compensação que agem na tentativa de manter o equilíbrio. Nessa linha de raciocínio, encontramos afirmações de que a articulação temporomandibular (ATM) e estruturas envolvidas são capazes de modificar-se de acordo com as forças sobre elas exercidas (Tay, 1994).

É consenso na literatura que atividades parafuncionais têm um alto impacto sobre as estruturas do sistema estomatognático e contribuem de forma significativa para o desenvolvimento da dor dos músculos mastigatórios e das desordens temporomandibulares (DTM) (Castelo PM. et al., 2005; Winocour E. et al., 2006; Manfredini, e Lobbezoo, 2010; Michelotti I. et al., 2010). Especificamente em relação ao bruxismo tem sido relatada sua associação com desordens musculares e desordens articulares (Barbosa et al., 2008) e mais pontualmente com dor miofascial e deslocamento de disco (Michelotti I. et al., 2010).

Entretanto, muitas formas de desordens articulares degenerativas, resultantes das sobrecargas, são clinicamente silenciosas e apenas diagnosticadas por meio de exames radiológicos. Em concordância, Wiese et al., em 2008, afirmaram que sinais clínicos e sintomas podem parecer pobres em termos de diagnóstico em relação aos achados radiográficos. Alterações ósseas e na cartilagem articular, visíveis radiograficamente, não se manifestam o suficiente para ser detectadas na avaliação clínica.

Nesse sentido, os recursos tecnológicos, implementados na área da saúde, são ilimitados e a tomografia computadorizada cone beam (TCCB) tornou-se um instrumento de alta determinação diagnóstica, inclusive na área odontológica.

A região da ATM é complexa pelos múltiplos elementos e tecidos que a compõem e as imagens obtidas por técnicas radiográficas convencionais oferecem informações pobres de detalhes, em virtude das distorções geométricas e volumétricas, assim como da sobreposição de imagens (Vanderberghe et al., 2008).

Mudanças na posição do côndilo na fossa articular foram avaliadas por TC de forma eficaz (Pullinger e White, 1995). No presente trabalho, na avaliação da relação horizontal côndilo-fossa, houve uma predominância da posição anteriorizada do lado direito e centralizada do lado esquerdo. Esse posicionamento predominante nos pacientes sugere um modo adaptativo do côndilo se alojar na fossa articular, uma vez que a oclusão apresenta interferências, próprias da fase de dentição mista. 
Na relação vertical côndilo-fossa, o predomínio encontrado foi da posição central para ambos os lados, pressupondo que não houve alterações inflamatórias ou degenerativas na maioria dos pacientes. Devido à dificuldade de encontrar parâmetros para análise morfométrica da região da ATM em crianças, os valores normais e alterados foram baseados nas médias de medidas da ATM realizadas em adultos. $O$ espaço articular entre côndilo mandíbular e fossa articular foi considerado aumentado quando apresentou valores maiores que $4 \mathrm{~mm}$ e diminuído quando menores de $1,5 \mathrm{~mm}$, valores intermediários foram considerados normais.

Especialistas em dor orofacial concordam que 0 côndilo se posiciona centralizadamente em relação à fossa articular no fechamento e abaixo do topo da eminência articular na abertura Wiese et al., (2008).

Ainda nessa ordem de idéias, relatos na literatura afirmam existir uma relação entre a posição do côndilo e o diagnóstico clínico de deslocamento de disco (Incesu et al., 2004; Bonilla-Aragon et al., 1999). Foi afirmado que a relação anormal entre côndilo e fossa, detectada radiograficamente, é o mais comum dos problemas de desarranjos internos da ATM (Incesu et al., 2004). Entretanto outros estudos têm demonstrado que uma posição não centralizada do côndilo, na fossa articular, não necessariamente é sinal de patologia, uma vez que pode ser um achado em pacientes assintomáticos (Pullinger et al., 1985; Blaschke e Blaschke, 1981). Não obstante, no presente trabalho realizado em crianças com bruxismo, fator desencadeante de DTM, a presença de dor à palpação nos músculos temporal e masseter associada à posição condilar foi encontrada de forma contralateral para o primeiro e ipsilateral à direita para o segundo.

Frente a esta controversa, apontada também por Senna et al., 2009 e Pereira et al., 2007, cabe salientar que a imagem poderia representar a possibilidade de prever possíveis manifestações sintomatológicas, uma vez que algumas alterações podem ocorrer de forma silenciosa, o que nos colocaria numa melhor posição para interceptá-las, principalmente se de crianças se trata.

Inusitadamente, na presente pesquisa aplainamentos foram encontrados em todos os pacientes (100\%), em um ou ambos os os lados, e osteófitos na maioria deles (70\%). Isto pode ser sugestivo da capacidade adaptativa da ATM ante a presença de uma parafunção, como relatado na literatura (Tay, 1994) Entretanto, em relação à presença de osteófitos foi observado resultado com significância estatística quando associado à dor na ATM no lado direito. 
Nessa linha de raciocínio, alguns autores também sugerem que algumas alterações ósseas, como as citadas anteriormente, fazem parte do processo de remodelação óssea (Wiese et al., 2011; Librizzi et al., 2011; Chen et al., 2009). Mesmo reconhecendo que o osso é um tecido dinâmico que sofre processos de remodelação constante, a presença dessas alterações em períodos tão precoces da vida, parece ser reflexo do desequilíbrio resultante de sobrecargas exercidas pelas parafunções sobre as estruturas, neste caso pelo bruxismo.

Em relação a escleroses e erosões, as mesmas não foram encontradas, podendo este fato ser explicado pela faixa etária dos pacientes avaliados, já que esses tipos de alterações ocorrem quando a parafunção tem estado presente por um longo período, como é o caso dos adultos.

No que diz respeito às assimetrias, observamos a diferença da relação côndilo-fossa, no sentido vertical e horizontal, dos lados direito e esquerdo. É inegável que existe assimetria no ser humano, desde uma perspectiva frontal como também axial. Nesse sentido, a fossa mandibular, o côndilo e estruturas adjacentes acompanham essa característica (Pirttiniemi et al., 1994).

Análises de assimetria em relação ao crânio e à face foram relatadas. Assim, verificou-se existir assimetria dos ossos cranianos de um modo geral e entre o lado esquerdo e direito da face (Lindblom, 1960). Diferenças entre ambos os lados da eminência articular, assimetria facial no terço superior da face, assimetria no movimento de abertura máxima da boca, assimetria facial relacionando os lados, associados à dores de cabeça e à DTM, também foram relatadas (Miller e Smidt, 1996; Vig e Hewitt, 1975).

Quando analisamos os resultados deste trabalho na perspectiva clínica, verificamos que, apesar de termos encontrado assimetria entre os lados direito e esquerdo, as diferenças não apresentaram significância estatística. Essa assimetria encontrada em nossa pesquisa não resultou em problemas disfuncionais do sistema estomatognático, com manifestações de sinais e sintomas significativos estatisticamente. Contudo, cabe salientar que qualquer desequilíbrio no processo de crescimento e desenvolvimento pode ser progressivo e se persistente, pode se tornar irreversível.

A existência insuficiente de referências bibliográficas com relação a alterações dos componentes da articulação temporomandibular (ATM) em crianças com bruxismo, na fase de dentição mista, poderia ter sido uma limitação para a discussão do presente trabalho. Entretanto, foi um dos fios condutores da procura de subsídios na tentativa de tecer elos com a diversidade de aspectos que envolvem o campo da complexidade morfofuncional da 
ATM e estruturas adjacentes, assim como do bruxismo como a atividade parafuncional com maiores efeitos deletérios.

Razões éticas não permitiram a avaliação por tomografia computadorizada cone beam (TCCB) de crianças sem bruxismo para constituir um grupo controle e estabelecer comparações entre pacientes saudáveis e os que apresentam a parafunção. Assim, como visto no decorrer do texto, tratou-se de um trabalho descritivo.

Mesmo que os resultados obtidos no presente trabalho não possam ser projetados e sejam apenas conclusivos para a população estudada, os achados referentes às alterações ósseas e da relação côndilo-fossa, associados a algum grau de dor nos músculos mastigatórios e ATM, são reflexo do impacto que o bruxismo têm sobre o sistema estomatognático e podem vir representar um alerta para a significância de avaliações que não se limitem apenas a um diagnóstico sintomático e sim etiológico. Nesse sentido o recurso diagnóstico da imagem pode tornar-se essencial. 


\section{Conclusão}

De acordo com os resultados obtidos, pode-se concluir que:

- Alterações ósseas tais como aplainamento, osteófitos e relação côndilofossa, fora do padrão de centralização, assim como assimetrias entre ambos os lados, estiveram presentes na população estudada.

- A presença de osteófitos do lado direito tem associação com dor na ATM ipsilateral.

- A posição do côndilo na fossa articular no sentido horizontal esta associada com a presença de dor no músculo temporal, contralateral.

- A posição do côndilo na fossa articular no sentido horizontal esta associada com a presença de dor no músculo masseter, ipsilateral.

- Os achados sugerem que o bruxismo pode promover alterações significativas nas estruturas do sistema estomatognático desde a infância. 
REFERÊNCIAS 


\section{REFERÊNCIAS}

1. Ahmad R. Bruxism in children. J. Pedontics 1986;10:105-26.

2. Bader G, Kampe T, Tagdae T. Body movement during sleep in subjects with long standing bruxing behavior. Int J Prosthodont 2000;13(4):327-33.

3. Bader G, Lavigne G. Sleep bruxism: an overview of an oromandibular sleep movement disorder. Sleep Medicine Reviews 2000;4:27-43.

4. Barbosa TS, Miyakoda LS, Pocztaruk RL, Rocha CP, Gavião MBD. Temporomandibular disorders and bruxism in childhood and adolescence: Review of the literature. International Journal of Pediatric Otorhinolaryngology 2008;72:299-314.

5. Blaschke DD, Blaschke TJ. Normal TMJ bony relationships in centric occlusion. J Dent Res 1981;60:98-104.

6. Bonilla-Aragon $\mathrm{H}$, Tallents $\mathrm{RH}$, Katzberg RW, Kyrkanides $\mathrm{S}$, Moss ME. Condyle position as a predictor of temporomandibular joint internal derangement. J Prosthet Dent 1999;82:205-8.

7. Brooks SL, Brand JW, Gibbs SJ, Hollender L, Lurie AG, Omnell Karl-Ake, Westesson Per-Lennart, White SC. Imaging of the temporomandibular joint: A position paper of the American academy of oral and maxillofacial radiology. Oral Surg Oral Med Oral Pathol Oral Radiol Endod 1997;83:609-18.

8. Castelo PM, Gavião MBD, Pereira LJ, Bonjardim LR. Relationship between oral parafunctional/nutritive sucking habits and temporomandibular joint dysfuntion in primary dentition. International Journal of Paediatric Dentistry 2005;15:29-36.

9. Chau ACM, Fung K. Comparison of radiation dose for implant imaging using conventional spiral tomography, computed tomography, and cone-beam computed tomography. Oral Surg Oral Med Oral Pathol Oral Radiol Endod 2009;107:559-65.

10.Chen J, Sorensen KP, Gupta T, Kilts T, Young M, Wadhwa S. Altered functional loading causes differential effects in the subchondral bone and condilar cartilage in the temporomandibular joint from young mice. Osteoarthritis Cartilage 2009;17(3):354-61. 
11. Díaz-Serrano KV, da Silva CBA, de Albuquerque S, Saraiva MCP, NelsonFilho $P$. Is there an association between bruxism and intestinal parasitic infestation in children? J Dent Child 2008;75:276-9.

12. Ferreira-Bacci A, Cardoso C, Díaz-Serrano KV. Behavior and stress in children with bruxism. Brazilian Dental Journal 2012 In press.

13. Fonseca CME, dos Santos MBF, Consani RLX, dos Santos JFF, Marchini L. Incidence of sleep bruxism among children in Itanhandu, Brazil. Sleep Breath 2011;15:215-20.

14. Hintze $\mathrm{H}$, Wiese M, Wenzel A. Cone beam CT and conventional tomography for the detection of morphological temporomandibular joint changes. Dentomaxillofac Radiol 2007;36(4):192-7.

15. Jervoe-Storm Pia-Merete, Hangner M, Neugebauer J, Ritter L, Zoller JE, Jepsen S, Frentzen M. Comparison of cone-beam computerized tomography and intraoral radiographs for determination of the periodontal ligament in a variable phantom. Oral Surg Oral Med Oral Pathol Oral Radiol Endod 2010;109:95-101.

16. Incesu L, Taskaya-Yilmaz N, Ogutcen-Toller M, Uzun E. Relationship of condilar position to disc position and morphology. European Journal of Radiology 2004;51:269-73.

17. Kato T, Rompré P, Montplaisir JY, Sessle BJ, Lavigne GJ. Sleep bruxism: An oromotor activity secondary to micro-arousal. J Dent Res 2001a;80(10):19404.

18. Kato T, Thie NMR, Montplaisir JY, Lavigne GJ. Bruxism and orofacial movements during sleep. Dental Clinics of North America 2001b;45(4):657-84.

19. Kato T, Montplaisir JY, Guitard F, Sessle BJ, Lund JP, Lavigne GJ. Evidence that experimentally induced sleep bruxism is a consequence of transient arousal. J dent res 2003a;82(4):284-8.

20. Kato T, Thie NMR, Huynh N, Miyawaki S, Lavigne GJ. Topical review: Sleep bruxism and the role of peripheral sensory influences. J Orofac Pain 2003b;17:191-213.

21. Lascala CA, Panella J, Marques MM. Analysis of the accuracy of linear measurements obtained by cone beam computed tomography (CBCT-New Tom). Dentomaxillofacial Radiology 2004;33:291-4.

22. Lavigne GJ, Montplaisir JY. Restless legs syndrome and sleep bruxism: Prevalance and association among Canadians. Sleep 1994;17(8):739-43. 
23. Lavigne GJ, Kato T, Kolta A, Sessle BJ. Neurobiological Mechanisms involved in sleep bruxism. Crit Rev Oral Biol Med 2003;14(1):30-46.

24. Lavigne GJ, Khoury S, Abe S, Yamaguchi T, Raphael K. Bruxism physiology and pathology: an overview for clinicians. Journal of Oral Rehabilitation 2008;35:476-94.

25. Librizzi ZT, Tadinada AS, Vallyaparambil JV, Lurie AG, Mallya SM. ConeBeam computed tomography to detect erosions of the temporomandibular joint: effect of field of view and voxel size an diagnostic efficacy and effective dose. Am J Orthod Dentofacial orthop 2011;140:25-30.

26. Lindblom G. On the anatomy and function of the temporomandibular joint. Acta Odontol Scand 1960;17(28):7-287.

27. Lobbezoo F, Lavigne GJ, Tanguay R, Montplaisir. The effect of the catecholamine precursor L-Dopa an sleep bruxism: A controlled clinical trial. Movement Disorders 1997;12:73-8.

28. Lobbezoo F, Naeije. Bruxism is mainly regulated centrally, not peripherally. Journal of Oral Rehabilitation 2001;28:1085-91.

29. Lobbezoo F, van der Zaag J, van Selms MKA, Hamburger HL. Principles for the management of bruxism. Journal of Oral Rehabilitation 2008;35:509-23.

30. Macaluso GM, Guerra P, Di Giovanni G, Boselli M, Parrino L, terzano MG. Sleep Bruxism is a disorder related to periodic arousals during sleep. J Dent Res 1998;77(4):565-73.

31. Manfredini D, Lobbezoo F. Role of psychosocial factors in the etiology of bruxism. J Orofac Pain 2009;23:153-66.

32. Manfredini D, Lobbezoo F. Relationship between bruxism and temporomandibular disorders: a systematic review of literature from 1998 to 2008. Oral Surg Oral Med Oral Pathol Oral Radiol Endod 2010;109:26-50.

33. Michelotti A, Ciofi I, Festa P, Scala G, Farella M. Oral parafunctions as risk factors for diagnostic TMD subgroups. Journal of oral Rehabilitation 2010;37:157-62.

34. Miller VJ, Smidt A. Condilar asymmetry and age in patients with an Angle's class II division 2 maloclusion. J Oral rehabil 1996;23:712-5.

35. Nilner M. relationships between oral parafunctions and functional disturbances and diseases of the stomatognathic system among children aged 7-14 years. Acta Odontol Scand 1983;41(3):167-72. 
36. Nagasawa S, Yoshida T, Tamura K, Yamazoe M, Hayano K, Arai Y, Yamada $\mathrm{H}$, Kasahara $\mathrm{E}$, Ito $\mathrm{M}$. Constrution of database for three-dimensional human tooth models and its ability for education and research - carious tooth models. Dental Materials journal 2010;29(2):132-7.

37. Okeson JP. Temporomandibular disorders in children. Pediatric Dentistry 1989;11(4):325-9.

38. Omnell NA; Petersson A. Radiography of the temporomandibular joint utilizing oblique lateral transcranial projections. Comparison of information obtained with standardized technique and individualized technique. Odont Revy 1976;26:77-92

39.Pereira LI, Gavião MB, Bonjardim LR, Castelo PM. Ultrasound and tomographic evaluation of temporomandibular joints in adolescents with and without signs and symptoms of temporomandibular disorders: a pilot study. Dentomaxillofac Radiol 2007;36(7):402-8.

40. Pirttiniemi PM, Associations of Mandibular and facial asymmetries: a rewiew. Am J Orthod Dentofac Orthop 1994;106:191-200.

41. Pratap-Chand R, Gourie-Devi M. Bruxism: its significance in coma. Clin Neurol Neurosurg 1985;87(2):113-7.

42. Pullinger AG, Hollender L, Solberg WK, Peterson A. A tomographic study of mandibular condyle position in an asymptomatic population. J Prosthet Dent 1985;53;706-13.

43. Pullinger AG, White SC. Efficacy of TMJ radiographs in terms of expected versus actual findings. Oral Surg Oral Med Oral Pathol Oral Radiol Endod 1995;79:367-74.

44. Roberts JA, Drage NA, Davies J. Thomas DW. Effective dose from cone beam CT examinations in dentistry. The British Journal of Radiology 2009;82:35-40.

45. Rodríguez K, Miralles R, Gutiérrez MF, Santander H, Fuentes A, Fresno MJ, Valenzuela $S$. Influence of jaw clenching and tooth grinding on bilateral sternocleidomastoid EMG activity. Cranio 2011;29(1):14-22.

46. Schenck CH, Mahowald MW. REM sleep behavior disorder: clinical, developmental, and neuroscience perspective 16 years after its formal identification in sleep. Sleep 2002;25(2):120-38.

47. Senna BR, Marques LS, França JP, Ramos-Jorge ML, Pereira LJ. Condyledisk-fossa position and relationship to clinical signs and symptoms of 
temporomandibular disorders in women. . Oral Surg Oral Med Oral Pathol Oral Radiol Endod 2009;108:117-24.

48. Serra-Negra JM, Paiva SM, Seabra AP, Dorella C, Lemos BF, Pordeus IA. Prevalence of sleep bruxism in a group of brazilian schoolchildren. European Archives of Paediatric Dentistry 2010;11(4):192-5.

49. von Stechow D, Balto K, Stashenko P, Muller R. Three-Dimensional quantitation of periradicular bone destruction by micro-computed tomography. Journal of Endodontics 2003;29(4):252-6.

50. Suomalainen A, Kiljunen T, Kaser Y, Peltola J, Kortesniemi M. Dosimetry and image quality of four dental cone beam computed tomography scanners. Dentomaxillofacial Radiology 2009;38:367-78.

51. Tachibana N, Yamanaka K, Kaiji R, Nagamine T, Watatani K, Kimura J, Shibasaki. Sleep bruxism as a manifestation of subclinical rapid eye movement sleep behavior disorder. Sleep 1994;17(6)555-8.

52. Tay DKL. Physiognomy in the classification of individuals with a lateral preference in mastication. J Orofac Pain 1994;8:61-72.

53. Vanderas AP, Manetas KJ. Relationship between malocclusion and bruxism in children and adolescents:a review. Pediatric Dentistry 1995;17(1):7-12.

54. Vandenberghe B, Jacobs R, Yang J. Detection of periodontal bone loss digital intraoral and cone beam computed tomography images: an in vitro assessment of bony and/or infrabony defects. Dentomaxillofacial Radiology 2008;37:252-60.

55. Vassileva J, Stoyanov D. Quality control and patient dosimetry in dental cone beam CT. Radiation Protection Dosimetry 2010;139(1):310-2.

56. Vig PS, Hewitt AB. Assimetry of the human facial skeleton. Asymmetry 1975;45:125-9.

57. Ware JC, Rugh JD. Destrutive bruxism: sleep stage relationship. Sleep 1988;11(2):172-81.

58. White SC, Heslop EW, Hollender LG, Mosier KM, Ruprecht A, Shrout MK. Parameters of radiologic care: An official report of the american academy of oral and maxillofacial radiology. Pathol Oral Radiol Endod 2001;91:498-511.

59. Wiese $M$, Hintze $H$, Svensson $P$, Wenzel A. comparison of diagnostic accuracy of film and digital tomograms for assessment of morphological changes in the TMJ. Dentomaxillifac Radiol 2007;36:12-7. 
60. Wiese M, Hintze H, Petersson A, Knutsson K, Bakke M, List T, Svensson P. Osseous changes and condyle position in TMJ tomograms: impact of $\mathrm{RDC} / \mathrm{TMC}$ clinical dignoses on agreement between expected and actual findings. Oral Surg Oral Med Oral Pathol Oral Radiol Endod 2008;106:52-63.

61. Wiese M, Wenzel A, Hintze H, Petersson A, Knutsson K, Bakke M, List T, Svensson $\mathrm{P}$. influence of croos-section temporomandibular joint tomography on diagnosis and management decisions of patients with temporomandibular joint disorders. J Orofac Pain 2011;25:223-31.

62. Winocour E, Littner D, Adams I, Morita M. Oral habits and their association with signs and symptoms of temporomandibular disorders in adolescents: gender comparison. Oral Surg Oral Med Oral Pathol Oral Radiol Endod 2006;102:482-7. 
Anexos 


\title{
ANEXO A - APROVAÇÃO DO COMITÊ DE ÉTICA
}

\author{
UNIVERSIDADE DE SÃO PAULO \\ Faculdade de Odontologia de Ribeirão Preto \\ Comitê de Ética em Pesquisa
}

Of. CEP / 444 / FORP

Ribeirão Preto, 29 de outubro de 2010

Ref. processo . $^{\circ}$ 2010.1.965.58.0

CAAE $n .^{\circ} 0058 \cdot 0.138 .000-10$

Senhora Pesquisadora:

Informamos que o Comitê de Ética em Pesquisa, em sua 114. ${ }^{\text {a }}$ sessão, realizada em 21/10/2010, aprovou o desenvolvimento do projeto de pesquisa envolvendo seres humanos, intitulado "Avaliação dos componentes anatômicos do sistema estomatognático de crianças com bruxismo, através de imagens obtidas por Tomografia Computadorizada Cone Beam".

$\mathrm{Na}$ oportunidade, lembramos da necessidade de serem entregues, na secretaria do CEP, o Relatório Parcial em 21/07/2011 e o Relatório Final em 21/04/2012, com os respectivos formulários preenchidos pelo pesquisador responsável.

Lembramos ainda que, quando da submissão dos relatórios a este Comitê, quaisquer inclusões ou modificações no projeto original deverão ser comunicadas e justificadas ao CEP, através do formulário supracitado.

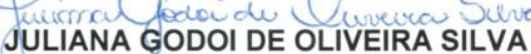

Secretária do Comitê de Ética em Pesquisa

IIma. Sra.

Profa. Dra. KRANYA VICTORIA DÍAZ SERRANO

Departamento de Clínica Infantil, Odontologia Preventiva e Social desta Faculdade

AVENIDA DO CAFÉ, S/N..$^{\circ}$ TEL. (16) 3602-4123/3963-FAX (16) 3602-4102 14040.904 - RIBEIRÃO PRETO - SP - BRASIL 


\title{
ANEXO B - TERMO DE CONSENTIMENTO LIVRE E ESCLARECIDO
}

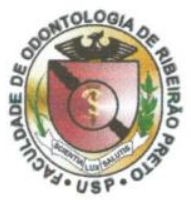

\author{
UNIVERSIDADE DE SÃO PAULO \\ FACULDADE DE ODONTOLOGIA DE RIBEIRÃO PRETO
}

TERMO DE CONSENTIMENTO LIVRE E ESCLARECIDO

(Capítulo IV, itens 1 a 3 da Resolução 196/96 - Conselho Nacional de Saúde)

Eu, Profa. Dra. Kranya Victoria Diaz Serrano e a Pós Graduanda lliana Ferraz Sabbatini, pesquisadoras responsáveis pelo projeto de pesquisa intitulado "Avaliação dos componentes anatômicos do sistema estomatognático de crianças com bruxismo, através de imagens obtidas por Tomografia Computadorizada Cone Beam " apresentamos aos responsáveis pelas crianças, o Termo de Consentimento Livre e Esclarecido, convidando às crianças a participar do referido projeto.

O objetivo do estudo será: Estudar os problemas que a criança possa apresentar na gengiva, nos dentes, nos ossos e nos músculos do rosto, como dor causada por apertamento ou rangimento dos dentes (bruxismo), por meio de exame clínico e de Tomografia computadorizada que parece com uma radiografia.

Os procedimentos a serem realizados serão:

Seleção das crianças que recebem tratamento na clinica de Odontopediatria FORP- USP;

Será preenchido um Questionário a ser respondido pelos responsáveis pelas crianças.

Será realizado um Exame clínico detalhado para ver se a criança tem os dentes desgastados, se tem dor nos músculos do rosto ou algum tipo de desconforto no osso da mandíbula.

Será realizado um exame que parece com Raio X (Tomografia Computadorizada Cone Beam), nas crianças com bruxismo, na clínica de diagnóstico DVI (Diagnóstico Volumétrico por Imagem) situada à Rua Sete de Setembro, 949 sob responsabilidade do Dr. Fernando Gonçalves Junqueira Leite, especialista em Radiologia CROSP 75381. O transporte dos pacientes, junto ao responsável, até este centro, será custeado pelos pesquisadores. Os exames de tomografia serão realizados sem custo algum para o paciente.

Análise crítica de riscos e benefícios:

- A presente pesquisa não apresenta riscos previsiveis ao paciente

Não é previsto o ressarcimento de despesas ou indenizações, já que os procedimentos a serem realizados não são agressivos à saúde fisica ou moral.

Os pesquisadores se comprometem a prestar assistência, caso ocorra algum problema relacionado à execuçăo

da parte clínica (atendimento do paciente) do projeto.

Como beneficios serão dadas as orientações aos responsáveis, para interromper o progresso dos problemas que o bruxismo possa ter trazido à criança.

Acompanhamento e assistência:

- Todos os procedimentos serão acompanhados pelos pesquisadores. Além disso, os mesmos oferecerão a assistência necessária durante a pesquisa.

Garantia de esclarecimentos:

Os participantes têm garantia de que receberão respostas a qualquer pergunta e esclarecimentos de qualquer dúvida quanto aos procedimentos, riscos e benefícios e outros assuntos relacionados com a pesquisa. Qualquer dúvida ou problema relativo à pesquisa deve ser comunicado com a maior brevidade possivel à P.G. Iliana Ferraz Sabbatini pelo telefone(16) 8168. 3637, à Profa. Kranya Victoria Díaz Serrano pelos telefones (16) 3911. 2374 ou 3602. 3995 e ao C.D. Fernando Gonçalves Junqueira Leite pelos telefones (16) 8159. 7667 ou (16) 3635. 9694.

Retirada do consentimento:

O responsável pela criança participante tem a liberdade de retirar seu consentimento a qualquer momento, deixando a criança de participar do estudo, sem penalização alguma e sem prejuízo do atendimento. 


\section{UNIVERSIDADE DE SÃO PAULO \\ FACULDADE DE ODONTOLOGIA DE RIBEIRÃO PRETO}

Garantia de sigilo:

- Será mantido sigilo quanto à identidade de todos os participantes na divulgação e publicação dos dados da pesquisa.

Resultados da pesquisa:

- Serão tornados públicos os resultados relativos à pesquisa, sejam eles favoráveis ou não.

Todas as informações contidas neste documento serão explicadas verbalmente, numa linguagem acessível ao voluntário.

Contato com o CEP (Comitê de Ética em Pesquisa):

Para esclarecimentos de eventuais dúvidas relativas à eticidade da pesquisa entrar em contato com a secretária Juliana Godoi de Oliveira Silva do Comitê de Ética em Pesquisa da FORP - USP,

situado à Avenida do Café S/N - TEL: (16) 3602. 4123.

Profa.Dra. Kranya Victoria Diaz Serrano CPF: 212566128-47
PG: Iliana Ferraz Sabbatini

CPF: 331.822 .468 .52

\section{CD: Fernando Gnçalves Junqueira Leite}

CPF: $218.940 .288-30$

Tendo recebido todas as orientações e estando de acordo, assino este termo

Nome do responsável pela criança

Assinatura do responsável pela criança

Ribeirão Preto de de 20 


\section{ANEXO C - PROTOCOLO PARA AVALIAÇÃO E DIAGNÓSTICO DE BRUXISMO}

FICHA NO

Data:

\section{DADOS PESSOAIS}

Nome:

Idade

Peso:

Data de Nascimento

Raça

Altura

Sexo:

Nome da Măe

Nome da Pai:

Nome do Responsável:

Fane

Endereço

* Pediatra ou Médico Assistente/ Instituiçấo:

A criança passa a maior parte do tempo em casa ( ) ou na escola ( )? Sob os cuidados de quem?

Obs.

MOTIVO DA CONSULTA-QUEIXA PRINCIPAL: 


\section{Antecedentes pré-natais:}

\begin{tabular}{|c|c|c|c|c|c|c|c|c|c|c|}
\hline \multicolumn{4}{|c|}{$\begin{array}{c}\text { 1. A senhora teve alguma enfermidade } \\
\text { durante a gestaçăo? }\end{array}$} & $\operatorname{Sim}^{1}$ & Nắa ${ }^{2}$ & Não sei ${ }^{8}$ & \multicolumn{4}{|c|}{ 2. Qual? } \\
\hline $\begin{array}{l}\text { 3. A ser } \\
\text { medicamento }\end{array}$ & $\begin{array}{l}\text { hora to } \\
\text { neste pe }\end{array}$ & $\begin{array}{l}\text { mou alg } \\
\text { lodo? }\end{array}$ & um & $\operatorname{Sim}^{1}$ & Não ${ }^{2}$ & Não sei ${ }^{8}$ & \multicolumn{4}{|c|}{ 4. Qual? } \\
\hline \multirow[t]{2}{*}{ 5. O parto foi } & \multirow[t]{2}{*}{ natural $^{1}$} & \multirow[t]{2}{*}{ cesárea $^{2}$} & \multirow{2}{*}{\multicolumn{2}{|c|}{ Forceps ${ }^{3}$}} & $\begin{array}{l}6 . \\
\text { complis }\end{array}$ & $\begin{array}{l}\text { Teve al } \\
\text { ação? }\end{array}$ & alguma & $\operatorname{Sim}^{1}$ & \multirow[t]{2}{*}{ Nă ${ }^{2}$} & Nấ sei ${ }^{8}$ \\
\hline & & & & & 7. Qua & & & & & \\
\hline
\end{tabular}

\section{Antecedentes neo-natais:}

\begin{tabular}{|l|l|l|l|l|l|l|}
\hline 8. A criança mamou no peito? & Sim $^{1}$ & Năo & 9. Por quanto tempo? & ( ) meses & ( ) anos \\
\hline $\begin{array}{l}\text { 10. A criança mamou na } \\
\text { mamadeira? }\end{array}$ & $\operatorname{Sim}^{1}$ & Năo $^{2}$ & 11. Por quanto tempo? & ( ) meses & ( ) anos \\
\hline $\begin{array}{l}\text { 12. A criança mamou ao a } \\
\text { mesmo tempo no peito e na } \\
\text { mamadeira? }\end{array}$ & Năo $^{2}$ & $\begin{array}{l}\text { 13. Que idade a criança tinha quando } \\
\text { foi introduzida a mamadeira? }\end{array}$ & $\begin{array}{l}\text { ( ) meses } \\
\text { ( ) anos }\end{array}$ \\
\hline
\end{tabular}

Dieta atual: agora a senhora vai receber este caderninho e vai preencher escrevendo tudo o que a criança comeu durante uma semana

$$
\text { Y INOICAR O PREENCHIMENTO DO DIARIO ALIMENTAR (Y SEMA NA) }
$$

Sono: a seguir serão realizadas algumas perguntas em relação à como tem sido, no último ano, o sono e a maneira de darmir da criança.

\begin{tabular}{|l|l|l|l|l|l|}
\hline $\begin{array}{l}\text { 14. No último ano a criança sempre tem } \\
\text { dormido no mesmo horário? }\end{array}$ & Năo $^{2}$ & Năo sei & \\
\hline $\begin{array}{l}\text { 15. No último ano a criança tem tido o } \\
\text { costume de dormir depois do almoço? }\end{array}$ & Nằo $^{1}$ & Năo sej & & \\
\hline
\end{tabular}




\begin{tabular}{|c|c|c|c|c|c|}
\hline \multicolumn{4}{|c|}{$\begin{array}{l}\text { 17. No último ano, durante a semana, a que horas a criança tem ido } \\
\text { geralmente dormir? }\end{array}$} & \multicolumn{2}{|l|}{ Horária } \\
\hline \multicolumn{4}{|c|}{ 18. No último ano, durante a semana, a que horas tem acordado? } & \multicolumn{2}{|l|}{ Horária } \\
\hline \multicolumn{4}{|l|}{ 19. Em geral, quantas horas dorme por dia? } & \multicolumn{2}{|l|}{$\mathrm{N}^{\circ}$ Horas } \\
\hline $\begin{array}{l}\text { 20. No último ano tem tido a costume de usar } \\
\text { travesseiro para dormir? }\end{array}$ & $\operatorname{Sim}^{1}$ & Năo ${ }^{2}$ & Nẫo sej ${ }^{8}$ & 21. Alto ${ }^{3} \mathrm{Ou}$ & Baix $\times 0^{4}$ \\
\hline \multirow{4}{*}{\multicolumn{2}{|c|}{$\begin{array}{l}\text { 22. Qual é a posiçăo em que a criança costuma } \\
\text { dormir? }\end{array}$}} & & Nä̊ sei ${ }^{8}$ & Lado E 1 & Lado $\mathrm{D}^{2}$ \\
\hline & & & \multicolumn{2}{|c|}{ Barriga para cima ${ }^{3}$} \\
\hline & & & & \multicolumn{2}{|l|}{ De bruços ${ }^{4}$} \\
\hline & & & & \multicolumn{2}{|c|}{$\begin{array}{l}\text { Interpondo as mäos no } \\
\text { rosto } 5\end{array}$} \\
\hline \multirow[t]{5}{*}{ 23. No último ana a criança teve pesadelos? } & $\operatorname{Sim}^{1}$ & Năo ${ }^{2}$ & Nấa sei ${ }^{8}$ & \multicolumn{2}{|c|}{ 24. Com que freqüência? } \\
\hline & & & & \multicolumn{2}{|l|}{$1 \times$ semana $^{1}$} \\
\hline & & & & \multicolumn{2}{|c|}{ Mais de $1 \times$ semana $^{2}$} \\
\hline & & & & \multicolumn{2}{|l|}{$1 \times$ mês $^{3}$} \\
\hline & & & & \multicolumn{2}{|c|}{ Mais de $1 \times$ mês $^{4}$} \\
\hline \multirow{5}{*}{$\begin{array}{l}\text { 25. Na último ana vocé alguma vez notou que } \\
\text { a criança tem parada de respirar enquanto } \\
\text { dorme? }\end{array}$} & $\operatorname{Sim}^{1}$ & Nắo ${ }^{2}$ & Não sei ${ }^{8}$ & \multirow{2}{*}{\multicolumn{2}{|c|}{\begin{tabular}{|l|} 
26. Com que freqüência? \\
$1 \times$ semana $^{1}$
\end{tabular}}} \\
\hline & & & & & \\
\hline & & & & \multicolumn{2}{|c|}{ Mais de $1 \times$ semana $^{2}$} \\
\hline & & & & \multicolumn{2}{|l|}{$1 \times$ mês $^{3}$} \\
\hline & & & & \multicolumn{2}{|c|}{ Mais de $1 x$ mês $^{4}$} \\
\hline $\begin{array}{l}\text { 27. No último ano a criança tem rancado à } \\
\text { noite? }\end{array}$ & $\operatorname{Sim}^{1}$ & Nắo ${ }^{2}$ & Não sei ${ }^{8}$ & & \\
\hline 28. A criança baba enquanto dorme? & $\operatorname{Sim}^{1}$ & Nắo ${ }^{2}$ & Não sei ${ }^{8}$ & & \\
\hline $\begin{array}{l}\text { 29. No último ano você alguma vez notou que } \\
\text { a criança tem falado enquanto dorme? }\end{array}$ & $\operatorname{Sim}^{1}$ & Nă̈o ${ }^{2}$ & Nẫo sej 8 & & \\
\hline 30. A criança acorda durante a noite? & $\operatorname{Sim}^{1}$ & Nẳo ${ }^{2}$ & Nẫo sei ${ }^{8}$ & \multicolumn{2}{|c|}{\begin{tabular}{|l|} 
31. Com que frequêência? \\
$1 \times$ noite $^{1}$
\end{tabular}} \\
\hline & & & & Mais de $1 \times n$ & noite ${ }^{2}$ \\
\hline
\end{tabular}


Preferência manual: eu precisa saber qual é a mầo que a criança mais utiliza.

\begin{tabular}{|c|c|c|c|}
\hline 32. Com que măo a criança escreve? & Direita $^{1}$ & Esquerda ${ }^{2}$ & Ambas $^{3}$ \\
\hline 33. Com que mâo a criança segura a colher? & Direita $^{1}$ & Esquerda? & Ambas $^{3}$ \\
\hline
\end{tabular}

Rotina quotidiana no último mês: agora vou fazer uma série de perguntas sobre as atividades diárias da criança.

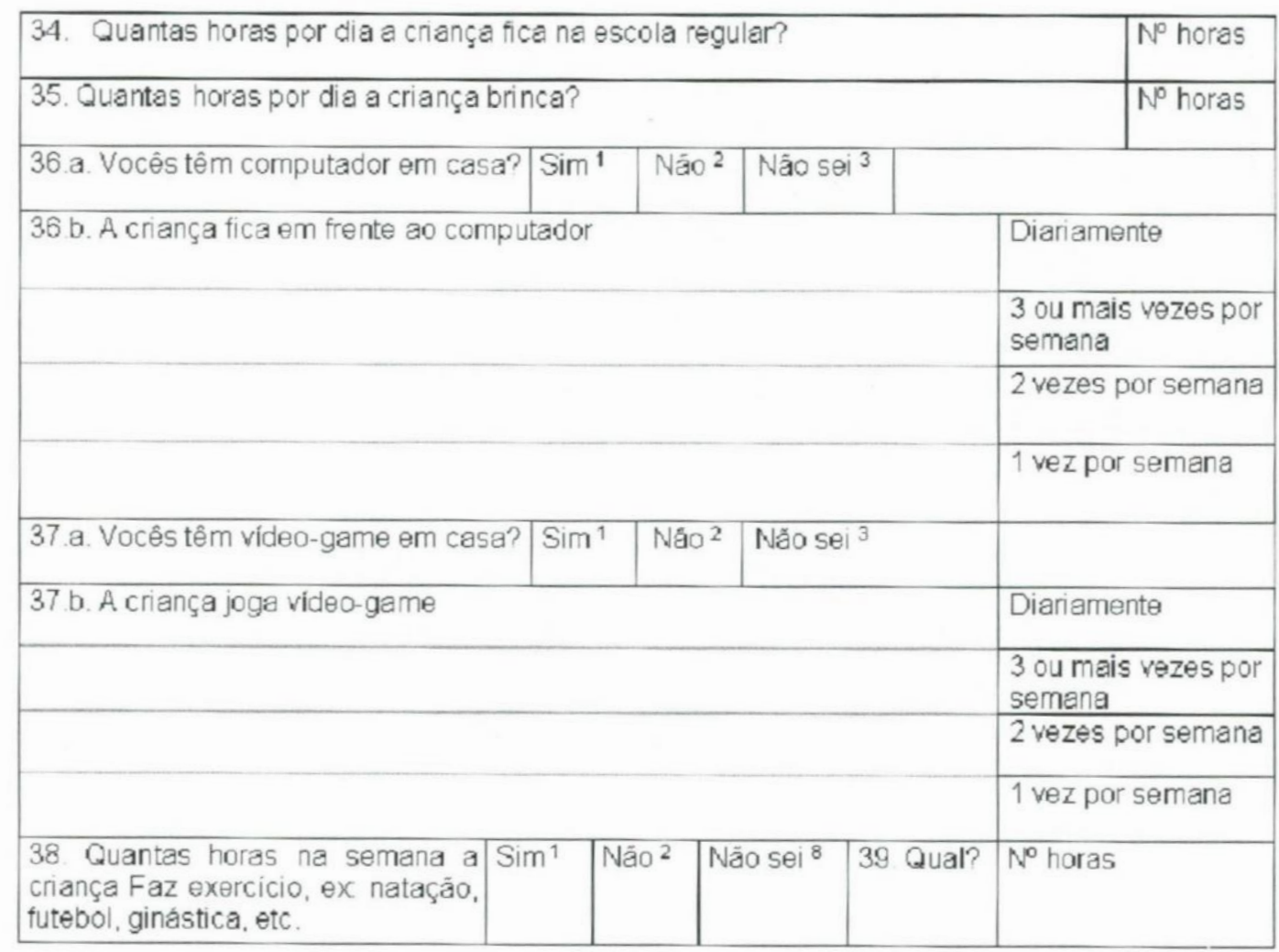

Obs 
Hábitos Parafuncionais: tềm crianças com alguns hábitos. A seguir farei uma sêrie de perguntas a esse respeito

\section{A criança...}

\begin{tabular}{|c|c|c|c|c|}
\hline \multirow{2}{*}{$\begin{array}{l}\text { 40. Em algum momento, mesma por } \\
\text { pouco tempo, chupou a dedo? } \\
\text { 42. Ainda chupa o dedo? }\end{array}$} & $\operatorname{Sim}^{1}$ & Năo ${ }^{2}$ & Não sei ${ }^{8}$ & $\begin{array}{l}\text { 41. Áté quando? } \\
\text { ( anos meses) }\end{array}$ \\
\hline & $\operatorname{Sim}^{1}$ & Nấ ${ }^{2}$ & Não sei 8 & \\
\hline \multirow{2}{*}{$\begin{array}{l}\text { 43. Em algum momento, mesmo por } \\
\text { pouco tempo, chupou chupeta? } \\
\text { 45. Ainda chupa chupeta? }\end{array}$} & $\operatorname{Sim}^{1}$ & Năo ${ }^{2}$ & Não sei ${ }^{8}$ & $\begin{array}{l}\text { 44. Até quando? } \\
\text { ( anos meses) }\end{array}$ \\
\hline & $\operatorname{sim} 1$ & Nấ2 ${ }^{2}$ & Nâo Sei ${ }^{8}$ & \\
\hline $\begin{array}{l}\text { 46. Em algum momento, mesma por } \\
\text { pouca tempo, teve o hábito de morder } \\
\text { objetos? } \\
\text { Ex caneta, brinquedos, blusa, etc. }\end{array}$ & $\operatorname{sim}^{1}$ & Nắ ${ }^{2}$ & Não sei ${ }^{8}$ & $\begin{array}{l}\text { 47. Até quando? } \\
\text { ( anos meses) }\end{array}$ \\
\hline $\begin{array}{l}48 \text { Nos últimos } 3 \text { meses tem-se } \\
\text { repetido esse hábito? }\end{array}$ & $\operatorname{Sim}^{1}$ & Năo ${ }^{2}$ & Não sei ${ }^{8}$ & \\
\hline \multirow[t]{3}{*}{$\begin{array}{l}\text { 49. Nos últimos } 3 \text { meses tem mascado } \\
\text { chiclete? }\end{array}$} & \multirow[t]{3}{*}{$\operatorname{sim}^{1}$} & \multirow[t]{3}{*}{ Náo? } & \multirow[t]{3}{*}{ Nắo sei ${ }^{8}$} & $\begin{array}{l}\text { 50. Cam que frequêência? } \\
\text { Diariamente } 1\end{array}$ \\
\hline & & & & $3 x$ semana $^{2}$ \\
\hline & & & & $1 x$ semana $^{3}$ \\
\hline \multirow{2}{*}{ 51. Teve o nabito de roer as unithas? } & $\operatorname{Sim}^{1}$ & Nă $0^{2}$ & Não sei ${ }^{8}$ & $\begin{array}{l}\text { 52. Até quando? } \\
\text { (anos meses) }\end{array}$ \\
\hline & $\operatorname{sim}^{1}$ & Năo ${ }^{2}$ & Não sei ${ }^{8}$ & \\
\hline 54 A criança morde a bochecha? & $\operatorname{Sim}^{1}$ & Năo ${ }^{2}$ & Não sei ${ }^{8}$ & \\
\hline $\begin{array}{l}\text { 55. A criança coloca a língua elou lábios } \\
\text { entre os dentes? }\end{array}$ & $\operatorname{Sim}^{1}$ & Nắo ${ }^{2}$ & Nắo sei 8 & \\
\hline 56. Teve o hábito de ranger os dentes? & $\operatorname{Sim}^{1}$ & Năo ${ }^{2}$ & Não sei ${ }^{8}$ & $\begin{array}{l}\text { 57. Até quando? } \\
\text { anos meses) }\end{array}$ \\
\hline $\begin{array}{l}\text { 58. Nos últimos } 3 \text { meses a criança tem } \\
\text { rangido os dentes? }\end{array}$ & $\operatorname{Sim}^{1}$ & Năo ${ }^{2}$ & Não sei ${ }^{8}$ & \\
\hline \multicolumn{4}{|l|}{ 59. Em que periodo da dia range os dentes? } & Noite ${ }^{2}$ \\
\hline 60. Teve o hábito de apertar os dentes? & $\mathrm{Sim}^{1}$ & Năo ${ }^{2}$ & Não sei ${ }^{8}$ & 61. Até quando? \\
\hline $\begin{array}{l}\text { 62. Nos últimos } 3 \text { meses a criança tem } \\
\text { apertado os dentes? }\end{array}$ & $\mathrm{Sim}^{1}$ & Năo ${ }^{2}$ & Nã́a sei ${ }^{8}$ & \\
\hline \multicolumn{4}{|l|}{ 63. Em que periodo do dia aperta os dentes? } & $\mathrm{Dia}^{1}$ \\
\hline
\end{tabular}


Alterações auditivas: muitas crianças sofrem de problema com os ouvidos. Será que citar nome já se queixou de

\begin{tabular}{|c|c|c|c|}
\hline 64. Ter sensação de ouvido tampado? & $\operatorname{Sim}^{1}$ & Nắa ${ }^{2}$ & Năo sei 8 \\
\hline 65. Com que frequeência? & Sempre ${ }^{1}$ & As vezes ${ }^{2}$ & Raramente ${ }^{3}$ \\
\hline 66. Escutar apitos no ouvido? & $\operatorname{Sim}^{1}$ & Năa ${ }^{2}$ & Năo sei ${ }^{8}$ \\
\hline 67. Com que frequêtncia? & Sempre ${ }^{1}$ & As vezes ${ }^{2}$ & Raramente $^{3}$ \\
\hline 68 Escutar zumbidas no ouvido? & $\operatorname{Sim}^{1}$ & Năo ${ }^{2}$ & Nắ sej ${ }^{8}$ \\
\hline 69. Com que freqüência? & Sempre ${ }^{1}$ & As vezes ${ }^{2}$ & Raramente $^{3}$ \\
\hline 70. A criança já se queixau de dor de ouvido? & $\operatorname{Sim}^{1}$ & Năo ${ }^{2}$ & Náo sei ${ }^{8}$ \\
\hline 71. com que frequância? & Sempre ${ }^{1}$ & As vezes ${ }^{2}$ & Raramente ${ }^{3}$ \\
\hline 72. A criança já teve infecçâo de ouvido? & $\operatorname{Sim}^{1}$ & Năo ${ }^{2}$ & Nắo sei ${ }^{8}$ \\
\hline 73. Com que frequêencia? & Sempre ${ }^{1}$ & Ás vezes ${ }^{2}$ & Raramente ${ }^{3}$ \\
\hline
\end{tabular}

Caracterizaçăo do quadro de dor: a seguir gostaria saber se a criança apresentou alguma dor na regiảo de cabeça elou pescoço.

\begin{tabular}{|c|c|c|c|c|}
\hline \multicolumn{2}{|l|}{$\begin{array}{l}\text { 74. Nos últimos três meses a criança tem se } \\
\text { queixado de dores de cabeça? }\end{array}$} & $\operatorname{Sim}^{1}$ & Nằ? & Năo sei 8 \\
\hline \multicolumn{2}{|l|}{ 75. Com que freqüência? } & Sempre ${ }^{1}$ & As vezes ${ }^{2}$ & Raramente ${ }^{3}$ \\
\hline 76. Em que área? & Năo sei ${ }^{8}$ & \multirow{2}{*}{\multicolumn{3}{|c|}{ 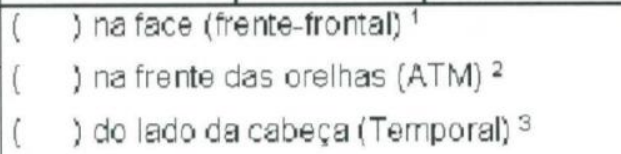 }} \\
\hline & & & & \\
\hline \multicolumn{2}{|c|}{$\begin{array}{l}\text { 77. Nos últimos três meses a criança tem se } \\
\text { queixado de dores no pescaço e nos ombros? }\end{array}$} & $\operatorname{Sim}^{1}$ & Nắa ${ }^{2}$ & Năo sei 8 \\
\hline \multicolumn{2}{|c|}{ 78. Com que frequência? } & Sempre ${ }^{1}$ & Ás vezes ${ }^{2}$ & Raramente $^{3}$ \\
\hline \multicolumn{2}{|l|}{$\begin{array}{l}\text { 79. Nos últimos três meses a criança tèm se } \\
\text { queixado de dor de dente? }\end{array}$} & $\operatorname{Sim}^{1}$ & Nẵo ${ }^{2}$ & Nắo sei ${ }^{8}$ \\
\hline \multicolumn{2}{|l|}{ 80. Com que freqüência? } & Sempre ${ }^{1}$ & Ás vezes ${ }^{2}$ & Raramente $^{3}$ \\
\hline
\end{tabular}


Avaliação da Oclusão: na hora de mastigar, falar ou mesmo sem fazer nada...

\begin{tabular}{|c|c|c|c|}
\hline $\begin{array}{l}\text { 81. A criança nas últimos três meses tem tido } \\
\text { dificuldade em abrir e fechar a baca? }\end{array}$ & $\operatorname{Sim}^{1}$ & Năo ${ }^{2}$ & Nắa sei ${ }^{8}$ \\
\hline 82. Com que frequência? & \multicolumn{2}{|c|}{ Constantemente ${ }^{1}$ ou } & Esporadicamente $^{2}$ \\
\hline $\begin{array}{l}\text { 83. A criança nas últimos três meses já ficou } \\
\text { com a mandibula travada? }\end{array}$ & $\sin ^{1}$ & Năo ${ }^{2}$ & Nắa sei ${ }^{8}$ \\
\hline 84. Com que freqüência? & \multicolumn{2}{|c|}{ Constantemente ${ }^{1}$ ou } & Esporadicamente ${ }^{2}$ \\
\hline
\end{tabular}

Constantemente $=1$ a $3 x$ semana

> Esporadicamente = periodos de tensäo: provas, competiçăo esportiva, aniversário, etc.

Antecedentes de ordem médica: a seguir as últimas perguntas serắo sobre a saúde geral da criança.

A criança...

\begin{tabular}{|c|c|c|c|c|c|}
\hline 85. Está sob tratamento médica? & $\operatorname{Sim}^{1}$ & Nãa ${ }^{2}$ & Năa sei ${ }^{8}$ & \multicolumn{2}{|l|}{ 86. Qual? } \\
\hline $\begin{array}{l}\text { 87. Está tomando algum } \\
\text { medicamento? }\end{array}$ & $\operatorname{Sim}^{1}$ & Não ${ }^{2}$ & Năa sei ${ }^{8}$ & \multicolumn{2}{|l|}{ 88. Qual? } \\
\hline 89. Já esteve hospitalizada? & $\operatorname{Sim}^{1}$ & $\mathrm{Nana}^{2}$ & Năa sei ${ }^{8}$ & 90. Quando? & 91. Por quê? \\
\hline 92. Já tomou anestesia geral? & $\operatorname{Sim}^{1}$ & $\mathrm{Nãa}^{2}$ & Năa sei ${ }^{8}$ & 93. Quando? & 94. Por quê? \\
\hline
\end{tabular}

A) Traumatismos: em relaçáo a acidentes, quedas, pancadas e batidas

\begin{tabular}{|l|l|l|l|l|l|}
\hline $\begin{array}{l}\text { 95. Alguma vez a criança teve algum } \\
\text { acidenterqueda e } \text { Sim }^{1}\end{array}$ & Năo ${ }^{2}$ & Năo sei ${ }^{8}$ & 96. Quando? \\
ejou cabeça?
\end{tabular}

abs 
B) Alérgicos: a senhora percebeu ou o médico já falou que a criança..

\begin{tabular}{|c|c|c|c|}
\hline 103.a. Respira de boca aberta? & $\mathrm{Sim}^{1}$ & Năo² & Não sei ${ }^{8}$ \\
\hline 103. b. Respira mais pela boca que pelo nariz? & $\operatorname{Sim}^{1}$ & Năa ${ }^{2}$ & Nâo sei ${ }^{8}$ \\
\hline 104. Tem ou teve rinite alérgica? & $\mathrm{Sim}^{1}$ & Năa ${ }^{2}$ & Não sei ${ }^{8}$ \\
\hline 105. Tem ou teve asma? & $\operatorname{Sim}^{1}$ & Nắo ${ }^{2}$ & Nấం sei ${ }^{8}$ \\
\hline 106. Tem ou teve bronquite? & $\operatorname{Sim}^{1}$ & Não ${ }^{2}$ & Nâo sei ${ }^{8}$ \\
\hline 107. Já operou das adenóides? & $\operatorname{Sim}^{1}$ & Nấo ${ }^{2}$ & Não sei ${ }^{8}$ \\
\hline 108. Já operou das amigdalas? & $\mathrm{Sim}^{1}$ & Năo ${ }^{2}$ & Năo sei ${ }^{8}$ \\
\hline
\end{tabular}

C) Neurológicos: agora vamos lembrar algumas coisas de quando a criança era pequena

\begin{tabular}{|c|c|c|c|c|}
\hline 109. A criança engatinhou? & $\operatorname{Sim}^{1}$ & $N a_{0}^{2}$ & Năo sei ${ }^{8}$ & \\
\hline 110. Com quanto tempo engatinhou? & & & & $>$ (8 meses) \\
\hline 111. Quando a criança começau andar? & & & & (74 meses) \\
\hline 112. Quando a criança começau falar? & & & & $>$ (2 anos: frases) \\
\hline 113. A criança já teve crises convulsivas? & $\operatorname{Sim}^{1}$ & Năo? ${ }^{2}$ & Não sei ${ }^{8}$ & 114 Quanda? \\
\hline
\end{tabular}

D) Reumáticos: a senhora sabe ou o médico já falou se a criança teve febre reumática?

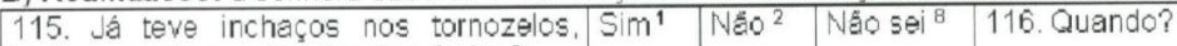
joelhos, punhos, cotovelo elou dedos?

E) Digestivos: e em relaçấo à barriga..

\begin{tabular}{|c|c|c|c|c|}
\hline 117. A criança já tomou remédio para vermes? & $\operatorname{Sim}^{1}$ & Nẫo ${ }^{2}$ & Năo sei ${ }^{8}$ & 118. Quando? \\
\hline 119. A criança tem ou teve gastrite? & $\operatorname{Sim}^{1}$ & Năo ${ }^{2}$ & Năo sei ${ }^{8}$ & 120. Quando? \\
\hline 121. A criança já apresentou fezes com sangue? & $\operatorname{Sim}^{1}$ & Nẫo $^{2}$ & Nấo sei ${ }^{8}$ & 122. Quando? \\
\hline 123. A criança tem diarréias frequentes? & $\operatorname{Sim}^{1}$ & Năo ${ }^{2}$ & Nắo sei ${ }^{8}$ & \\
\hline 124. A criança tem dores de barriga? & $\operatorname{Sim}^{1}$ & Nấ ${ }^{2}$ & Nāo sei ${ }^{8}$ & \\
\hline
\end{tabular}




\begin{tabular}{|l|l|l|l|}
\hline 125. A criança tem vômitos freqüentes? & $\operatorname{Sim}^{1}$ & $N^{2} 0^{2}$ & Não sei \\
\hline 126. A criança tem prisóes de ventre frequentes? & $\operatorname{Sim}^{1}$ & Năo & \\
\hline
\end{tabular}

F) Psicológicos: para acabar, algumas perguntas sobre o jeito de ser da criança.

\begin{tabular}{|c|c|c|c|c|}
\hline \multirow{3}{*}{\multicolumn{2}{|c|}{ 127. A senhora acha que seu filho é }} & Timida ${ }^{1}$ & Aglado ${ }^{4}$ & Introvertido ${ }^{7}$ \\
\hline & & Calmo 2 & Nervoso 5 & Extrovertido ${ }^{8}$ \\
\hline & & Medraso ${ }^{3}$ & Ansioso 6 & Comunicativo $^{9}$ \\
\hline 128. A criança já foi ou vai ao psicólogo? & Sim 1 & Não ${ }^{2}$ & Nẫo sei ${ }^{8}$ & 129. Quando? \\
\hline
\end{tabular}

DIAGNÓSTICO

POSSIVEIS FATORES ETIOLOGICOS

PROGNÓSTICO E CONDUTAS TERAPËUTICAS 
FICHA NO

Nome:

Nome do Responsável:

\section{AVALIAÇÃO CLINICA}

Obs: O profissional deve-se sentar de frente ao paciente, nesta tase da avaliaçăo.

Eu preciso que você me responda algumas coisas importantes enquarto te examino.

"Clessificaçăo

Respiração:

\begin{tabular}{|l|l|}
\hline Mista $^{4}$ & Bucal $^{2}$ \\
\hline Periodo Diurno & \\
\hline
\end{tabular}

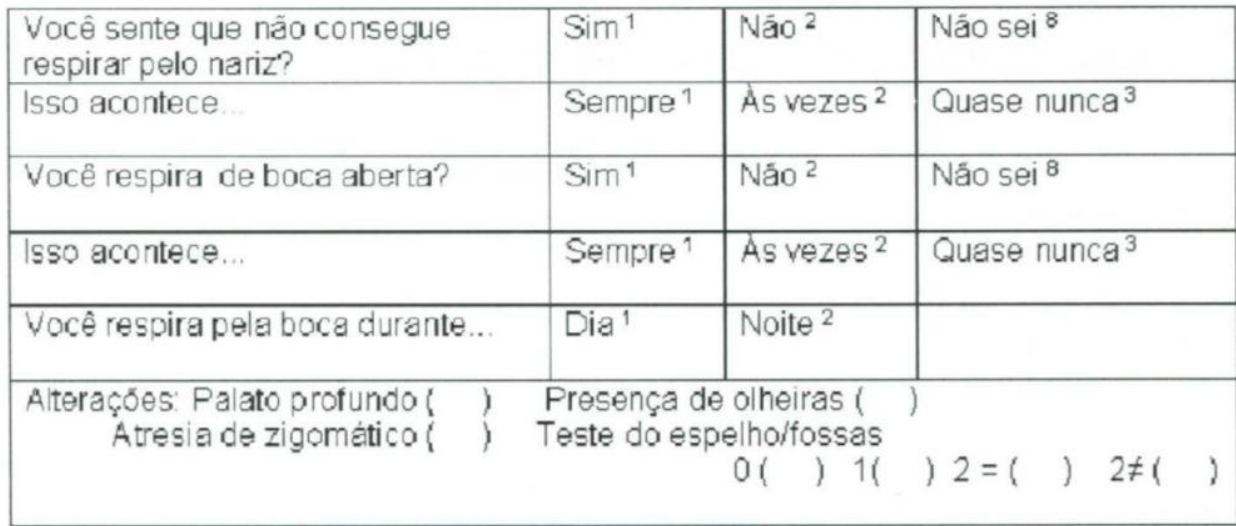

* Classificação

Deglutição:

\begin{tabular}{|l|l|l|l|}
\hline Normal & Atípica & Adaptada & Compensatória \\
\hline
\end{tabular}

\begin{tabular}{|c|c|c|c|}
\hline Interposiçāo de língua & \multicolumn{2}{|c|}{ Interposição de lábios } & \\
\hline Músculo Mental & Contração excessiva & Sem contraçăo & Contraçáo leve \\
\hline Músculos elevadores & Contração excessiva & Sem contraçăo & Contraçáo nomal \\
\hline
\end{tabular}




\begin{tabular}{|c|c|c|c|c|c|c|}
\hline \multirow{2}{*}{ Mastigação: } & \multicolumn{3}{|c|}{ 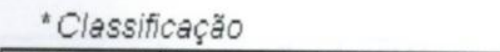 } & \multicolumn{3}{|c|}{${ }^{\text {"Quejxa de Dor }}$} \\
\hline & Unilateral & Direita & Esquerda & $\operatorname{Sim}^{1}$ & Nắa & Nă $a$ sei \\
\hline & Bilateral & Alternada & Simultânea & \begin{tabular}{|l|l|} 
Direito $^{1}$ & $E$ \\
\end{tabular} & Esquerdo ${ }^{2}$ & Ambos ${ }^{3}$ \\
\hline \multicolumn{3}{|c|}{$\begin{array}{l}\text { Já no tou se vocế mastiga de um } \\
\text { lado só? }\end{array}$} & $\mathrm{Sim}^{1}$ & Nẫo ${ }^{2}$ & \multicolumn{2}{|l|}{ Năo sei ${ }^{\theta}$} \\
\hline \multicolumn{3}{|c|}{ Isso acontece... } & Sempre ${ }^{1}$ & As vezes ${ }^{2}$ & \multicolumn{2}{|c|}{ Quase nunca ${ }^{3}$} \\
\hline \multicolumn{3}{|c|}{$\begin{array}{l}\text { Já sentiu dor no rosto na hora de } \\
\text { mastigar? }\end{array}$} & $\operatorname{Sim}^{1}$ & Nẫo $^{2}$ & \multicolumn{2}{|l|}{ Năo sei ${ }^{8}$} \\
\hline \multicolumn{3}{|c|}{ Isso acontece... } & Sempre ${ }^{1}$ & Ás vezes ${ }^{2}$ & \multicolumn{2}{|c|}{ Quase nunca ${ }^{3}$} \\
\hline \multicolumn{3}{|c|}{ De que lado sente a dor? } & Direita 1 & Esquerdo ${ }^{2}$ & \multicolumn{2}{|l|}{ Ambos $^{3}$} \\
\hline \multicolumn{3}{|c|}{$\therefore$ Testa da goma de mascar } & Direita 1 & Esquerdo ${ }^{2}$ & \multicolumn{2}{|c|}{ Alternado ${ }^{3}$} \\
\hline
\end{tabular}

Hábitos Parafuncionais: têm algumas crianças com muitos costumes diferentes e nós gostariamos de saber se vacê já fez ou faz alguma dessas caisas.

\begin{tabular}{|l|l|l|l|}
\hline Dedo & Chupeta & Marder objetos & Interpasiçáo de língua e lábios \\
\hline Goma de mascar & Roer unhas & Marder bochecha & Bruxismo \\
\hline
\end{tabular}

\begin{tabular}{|c|c|c|c|c|}
\hline Você já chupou o dedo? & $\mathrm{Sim}^{1}$ & Não 2 & Năo sei ${ }^{8}$ & $\begin{array}{l}\text { Até quando? } \\
\text { i anos meses) }\end{array}$ \\
\hline Ainda chupa o dedo? & $\mathrm{Sim}^{1}$ & Nẫ ${ }^{2}$ & Náo sei ${ }^{8}$ & \\
\hline Você já chupou chupeta? & $\operatorname{Sim}^{1}$ & Não ${ }^{2}$ & Nấo sei ${ }^{8}$ & $\begin{array}{l}\text { Até quando? } \\
\text { ( anos meses) }\end{array}$ \\
\hline Ainda chupa chupeta? & $\operatorname{Sim}^{1}$ & Não ${ }^{2}$ & Nấo sei ${ }^{8}$ & \\
\hline $\begin{array}{l}\text { Vocẽ tem o costume de morder objetos? } \\
\text { Ex caneta, brinquedos, etc. }\end{array}$ & $\operatorname{Sim}^{1}$ & Não ${ }^{2}$ & Năo sei ${ }^{8}$ & $\begin{array}{l}\text { Até quando? } \\
\text { ( anas meses) }\end{array}$ \\
\hline \multirow[t]{3}{*}{ Você masca chiclete? } & \multirow[t]{3}{*}{$\operatorname{Sim}^{1}$} & \multirow[t]{3}{*}{ Não ${ }^{2}$} & \multirow[t]{3}{*}{ Nẫo sei ${ }^{8}$} & $\begin{array}{c}\text { Com que freqüância? } \\
\text { Diariamente }\end{array}$ \\
\hline & & & & $3 x$ semana $^{2}$ \\
\hline & & & & $1 \times$ semana $^{3}$ \\
\hline Você já roeu as unhas? & $\operatorname{Sim}^{1}$ & Nâo ${ }^{2}$ & Não sei ${ }^{8}$ & $\begin{array}{l}\text { Até quando? } \\
\text { ( anos meses) }\end{array}$ \\
\hline Ainda roe as unhas? & $\operatorname{Sim}^{1}$ & Não ${ }^{2}$ & Nấo sei ${ }^{8}$ & \\
\hline Você morde a bachecha? & $\operatorname{Sim}^{1}$ & Nẫo ${ }^{2}$ & Nẫo sei ${ }^{8}$ & \\
\hline $\begin{array}{l}\text { Você tem o costume de par a língua } \\
\text { efou läbias entre os dentes? }\end{array}$ & $\operatorname{Sim}^{1}$ & Não ${ }^{2}$ & Năo sei ${ }^{8}$ & \\
\hline
\end{tabular}




\begin{tabular}{|c|c|c|c|c|c|}
\hline Você já notou se range os dentes? & $\operatorname{Sim}^{1}$ & Náo ${ }^{2}$ & Nắ sei ${ }^{8}$ & \multicolumn{2}{|c|}{$\begin{array}{l}\text { Até quando? } \\
\text { ( anos meses) }\end{array}$} \\
\hline Ainda range os dentes? & $\operatorname{Sim}^{1}$ & Năo ${ }^{2}$ & Nắa sei ${ }^{8}$ & & \\
\hline \multicolumn{4}{|l|}{ Você range as dentes durante... } & $\mathrm{Dia}^{1}$ & Noite ${ }^{2}$ \\
\hline E apertar os dentes, você já fez isso? & $\operatorname{Sim}^{1}$ & Nấo ${ }^{2}$ & Năo sei ${ }^{8}$ & \multicolumn{2}{|c|}{$\begin{array}{l}\text { Até quando? } \\
\text { ( anos meses) }\end{array}$} \\
\hline Ainda aperta os dentes? & $\operatorname{Sim}^{1}$ & Năo ${ }^{2}$ & Năo sei 8 & & \\
\hline \multicolumn{4}{|l|}{ Vocé aperta os dentes durante... } & Dia ${ }^{1}$ & Noite ${ }^{2}$ \\
\hline
\end{tabular}

Facetas de desgaste dentário: ${ }^{\star}$ Classificaçăo

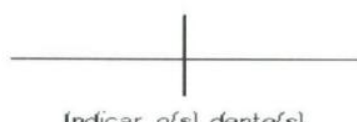

\begin{tabular}{|l|l|}
\hline & Grau 0 (Năo apresenta) \\
\hline & Grau 1 (Somente no esmalte) ${ }^{2}$ \\
\hline & Grau 2 (Dentina exposta) ${ }^{3}$ \\
\hline Grau 3 (Desgaste soverolexposiçăo pulpar) ${ }^{4}$ \\
\hline
\end{tabular}

Caracterização do quadro de dor: agora eu vou pôr minha mão em algumas áreas e você vai dizer se já sentiu dor nesse lugar, e com esta régua vai me indicar se foi suave ou forte

\begin{tabular}{|l|l|l|l|l|l|l|l|l|}
\hline Lado Direito & Face & ATM & Pescoço & Trapézio & Costas & Cabeça & Dentes & Ouvido \\
\hline Lado Esquerdo & Face & ATM & Pescoço & Trapézio & Costas & Cabeça & Dentes & Ouvido \\
\hline
\end{tabular}

OBS: - 


\begin{tabular}{|l|l|l|l|l|}
\hline $\begin{array}{l}\text { Impressões dentais em } \\
\text { bochechas }\end{array}$ & $\mathrm{Sim}^{1}$ & $\mathrm{Não}^{2}$ & Perdido & $\begin{array}{l}\text { Lado D ( ) } \\
\text { Lado E ( ) }\end{array}$ \\
\hline Impressões dentais em língua & $\mathrm{Sim}^{1}$ & $\mathrm{Não}^{2}$ & Perdido & $\begin{array}{l}\text { Lado D ( ) } \\
\text { Lado E ( ) }\end{array}$ \\
\hline
\end{tabular}

Fraturas de restaurações:

\begin{tabular}{|l|l|l|}
\hline $\operatorname{Sim}^{1}$ & Não & Perdido \\
\hline
\end{tabular}

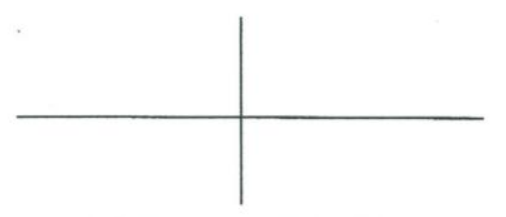

Indicar o(s) dente(s)

Fraturas dentais:

\begin{tabular}{|l|l|l|}
\hline Sim & Não & Perdido \\
\hline
\end{tabular}

*Intensidade das fraturas dentais

\begin{tabular}{|l|l|l|}
\hline Esmalte $^{1}$ & Dentina $^{2}$ & Dentina e Polpa expostos \\
\hline
\end{tabular}

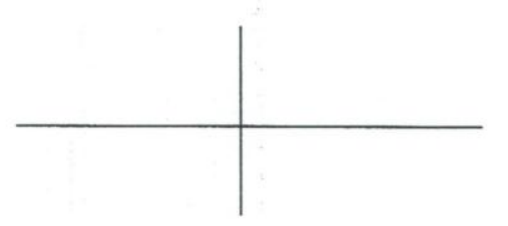

Indicar o(s) dente(s)

Perdido
Lado D ( ) Lado E ( ) 


\section{Avaliação da Oclusão:}

\begin{tabular}{|c|c|c|c|}
\hline $\begin{array}{l}\text { Você sente dor na hara de abrir e } \\
\text { fechar a boca? }\end{array}$ & Sim 1 & Nắa 2 & Nắo sei 8 \\
\hline & Sempre 1 & As wezes 2 & Quase nunca ${ }^{3}$ \\
\hline $\begin{array}{l}\text { Você sente dificuldade em abrir e } \\
\text { fechar a boca? }\end{array}$ & $\operatorname{Sim} 1$ & Nắa ${ }^{2}$ & Não sei ${ }^{8}$ \\
\hline & Sempre 1 & As vezes ${ }^{2}$ & Quase nunca ${ }^{3}$ \\
\hline Sua boca jấ ficou travacda? & $\operatorname{Sim} 1$ & Năo ${ }^{2}$ & Nấo sẹ ${ }^{8}$ \\
\hline & Sempre ${ }^{1}$ & As wezes ${ }^{2}$ & Quase nunca $^{3}$ \\
\hline
\end{tabular}

Obs

Em caso de dor, determinar a ărea (associar cam as músculos pterigádeo médio e lateral).

* Limite da Abertura bucal: me dir a valor dos de dos junt os

Agora vacê vai juntar estes 3 dedos e nesta pasição vai levá-los na sua baca.

\begin{tabular}{|l|l|}
\hline & a 2 dedos (limitaçĕo severa) \\
\hline $\begin{array}{l}3 \text { dedos (imitaçéo moderada) } \\
\text { + que } 3 \text { dedos (sem lmitaçä́) }\end{array}$ \\
\hline
\end{tabular}

Valor em mm:

\section{* Trajetória de abertura/fechamento:}

( ) simétrica ( ) desviada _

"Lateralida de:

( ) Interferềncias

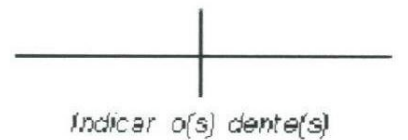

_ Trabalho

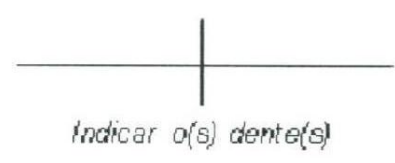

( =) Interferência Pasterior
Obs:

\section{Balanceio}

Obs:

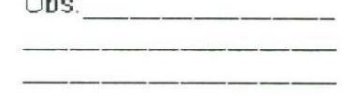

E 
`RELAÇÃO INTERMAXILAR:

\begin{tabular}{|l|l|}
\hline & Normo-aclusáo \\
\hline & Maloclusắo \\
\hline
\end{tabular}

Regiẫo anterior

Desvio da linha média ( ) NÃo

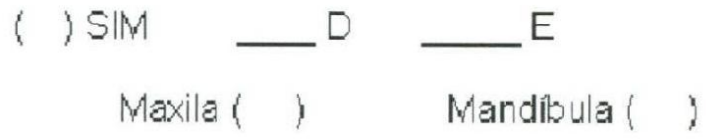
Overjet ( $) 0=m$. cruzada ant. Overbite ( ) $0=m$. aberta ant $1=$ topo a topo $\quad 1=$ topo a topa
$2=$ normal
$2=$ normal
$3=$ moderado (entre 3 e $6 \mathrm{~mm}$ )
$3=$ moderado (entre 3 e $6 \mathrm{~mm}$ )
$4=$ acentuado (mais que $6 \mathrm{~mm}$ ) $4=$ acentuado (mais que $6 \mathrm{~mm}$ )
$5=$ em erupção
$5=$ em erupçắo

Canino primário elou permanenfe
( ) ) Normo-oclusão
( ) ( ) Disto-oclusão
( ) ( ) Mésio-oclusão

\section{Regiâ posterior}

Molar primáno:

() )Reto ( ) ( ) Degrau mesial ( ) ) Degrau distal

Molar permanente:

( ) ( ) Norma-oclusão

( ) ( ) Dista-oclusão

( ) ( ) Mésio-oclusẫo

Mordida cruzada posterior: ) NÅO ( ) SIM _unilateral bilateral 
Palpação da ATM:

${ }^{*}$ Dor

$$
S \mid M()
$$

NÄO ( )

Lateral

Grau) D

( Grau) E

Posterior

Grau) D

( Grau) E

* Ruida detectado:

$S \mid M()$

NÃO( )

Estalid

( Grau) D

(Grau) $E$

Crepitaçăo ( Grau) D

Grau) E

Ruido referido

\begin{tabular}{|l|l|l|l|}
\hline $\begin{array}{l}\text { Você já sentiu fazer um barulho } \\
\text { nesta área? (mostrar a área) }\end{array}$ & Sim $^{1}$ & Nắo $^{2}$ & Nã́a sei \\
\hline Issa acontece... & Sempre $^{1}$ & Ȧs vezes $^{2}$ & Quase nunca $^{3}$ \\
\hline
\end{tabular}

Obs.

\section{Palpação muscular:}

"Manifestação de Dor.

\begin{tabular}{|c|c|c|c|c|}
\hline Porçáo anteriar do Temparal & c & Grau) D & i & Grau\} E \\
\hline Porção média do Temporal & & Grau) D & 1 & Grau) E \\
\hline Porçâo posterior do Temporal & & Grau) D & 1 & Grau, E \\
\hline Masseter superficial & & Grau) D & 1 & Grau: \\
\hline Masseter profundo & & Grau) D & ( & Graul E \\
\hline Músculas cervicais & & Grau) D & ( & Grau) E \\
\hline Estemocleidomastóideo & & Grau) D & ( & (lad) \\
\hline Trapézio & & Grau) D & ( & u) \\
\hline
\end{tabular}


Assimetria facial:

() NÃO ( ) SIM Descrição:

Postura Corporal: marcar os desvios da normalidade.

Vista lateral (acentuaçäo da curvatura cervical)! ) NÄO ( ) SIM (acentuaçảo da curvatura lombar) ( ) NÄO ( ) SIM

Vista lateral (relaçâo o mbrolorelha) [abdốmen em protrusãa]

Vista frontal (ombros desnivelados)

(quadris desnivelados)

Vista por trás (escáp ula alada)
( ) NAOO ( ) SIM

( ) ] N

( ) NÃO ( ) SIM

( ) NAO ( ) SIM

() NÂO I SIM

Avaliação comportamental dos paisıresponsável pelo profissional:

\begin{tabular}{|l|l|l|}
\hline Autoritário (a) & $\operatorname{Sim}^{1}$ & Não ${ }^{2}$ \\
\hline Superprote tor (a) & $\operatorname{Sim}^{1}$ & Nằo \\
\hline Ausente & $\operatorname{Sim}^{1}$ & Năo \\
\hline Presente & $\operatorname{Sim}^{1}$ & Nẫo $^{2}$ \\
\hline
\end{tabular}

Avaliação comportamental da criança pelo profissional:

\begin{tabular}{|c|c|c|}
\hline Tímido ${ }^{1}$ & Agitada 4 & Introvertido ${ }^{7}$ \\
\hline Calmo ${ }^{2}$ & Nervoso 5 & Extrovertido ${ }^{8}$ \\
\hline Medroso 3 & Ansiaso ${ }^{6}$ & Comunicativo $^{9}$ \\
\hline
\end{tabular}

